\title{
Differential Incremental Equilibrium Geometry-Effects of Cerebral Groove and Protein Granule Motion on Thinking Space and Mental Activity
}

\author{
Zhu Rongrong \\ DIEG Mathematics Research of HR, Fudan University, Shanghai, China
}

Email address:

rongrongzhu1969@163.com

To cite this article:

Zhu Rongrong. Differential Incremental Equilibrium Geometry-Effects of Cerebral Groove and Protein Granule Motion on Thinking Space and Mental Activity. American Journal of Applied Mathematics. Vol. 8, No. 3, 2020, pp. 98-122. doi: 10.11648/j.ajam.20200803.14

Received: April 16, 2020; Accepted: May 3, 2020; Published: May 27, 2020

\begin{abstract}
The research direction of this paper is to construct brain-like spatial structure and brain, nervous system and neurotransmitters from molecular cytobiology to construct mental acquisition from the influence of neuron and genome expression on brain, especially the material suspension caused by mental collapse to the neuron-like topological spatial structure and fluid topological structure of neurotransmitters. The spatial construction of acquired immunity and fluid morphology of neurotransmitters in the field of psychiatry (Carrying schizophrenia and other factors) also has brain-like mental activity traits. Stable traceability of neurotransmitter structure of series signal in schizophrenics with advanced intelligence. The high-end hyperspherical convex spherical fiber bundles with reduced dimension in $3+1$ dimension system, special light field with radiation, and the collapse of mental force cause the suspension of substance in stationary state, the similar solution of solitary wavelet of petal-like micro-fibers in superimposed bundles. That is to say, the intelligent information particles carrying special image fragments in the form of mental energy in Psychological Acquired Immunity. Including primitive and innovative mathematical models of neuronal cell modification. Therefore, on the basis of original mathematical "differential incremental equilibrium geometry". The geometric models of spatial geometry and fluid structure of neurotransmitters of all neurons in life sciences are solved at the molecular level. Even using the nonlinearity of 4-dimensional super-high-end super-spherical convex fiber plexus "redundancy, petal-like micro-fibers" Sex-like solitary wavelet, which truly establishes the internal structure and law of molecular cell biology model. Reflects the new field of human brain research. It provides the basis and precondition of theory and application for the establishment of hybrid artificial intelligence of life and machine. and has far-reaching influence and important development prospects for the development of artificial intelligence, especially in brain-like artificial intelligence.
\end{abstract}

Keywords: Cell Modification, Neurons, Neurotransmitters, Acquired Psychoimmunity, Quasi Brain Science, Nonlinear Solitary Wavelet

\section{Introduction}

In this paper, the trend of bud nucleus growth is described scientifically by cross-section: the trend of neurons, neuron cell bodies, dendrites and axons, neuron damage cell modification nucleus morphology the discharging frequencies of population vectors and movement directions of neurons (radioactive high-dimensional residual space structure), axons and thinking of spinal nerve (thinking structure) neurons (thinking structure). Protein structure of the "bud nucleus growth trend".
The growth trend of bud nucleus is the trend of human memory gene, sulcus and protein movement, in order to solve the problem of 4-dimensional super-high-end superglobular convex globular fibrous plexus-memory gene, sulcus-secondary incremental equilibrium space-s1dimensional+s2-dimensional "residual-like stacked petallike micro-fibers" embedded in the globular domain (intrinsic fold), and has "typical domain core-intrinsic fold". The Quasi-mobile communication structure of complex variable non-holomorphic univalent function and bivalent function exists simultaneously in the Quasi- 
mobile communication structure. The collapse of the 4dimensional super-high-end superspherical convex spherical fibers cluster-disordered mental force causes the suspension of matter to rest. The quadratic microincremental equilibrium space-s1-dimensional + s2dimensional "coproduct_ quasi-petal micro-fibers" thinking energy equation-spherical polar coordinate system. Formation of acquired mental immunity.

Trend of Bud Nucleus Growth-Trend of Thinking-Related Protein and Memory Crack-Radioactive Structure, Memory Crack, and Neuron-Synapse-Neurotransmitter-Flow Structure, Neuron-Cell Modification-Cell Core Division-Binuclear 4Polymer Protein, Memory Crack-Radioactive Structure "Trend of Bud Nucleus Growth". and Neuron-Synapse-Spirit There are neurons (sarcoplasmic reticulum (SR) membranous cannula_protein)_neurotransmitter_glutamicacid_chromosomed egeneration_cellmodification_cell_nucleus division_memorycleft_radioactivity structure. and neurons (SR) membranous cannula_protein)_neurotransmitter_glutamic acid (variation)_chromosome degeneration_cellmodification_at the same time, Cell nucleus division memory cleavage radioactivity structure.

The nucleus growth trend of neuron-cell modified-cell nucleus division-binuclear 4-mer protein. and the cell body composed of thinking structure variation + intrinsic structure of neuron nucleus, and carrying binuclear 4-mer protein. "Mononuclear 4 Polymer Protein" and "Binuclear 4 Polymer Protein" have a "neurobiological" relationship. Neurons memory fissure (thinking) neurotransmitter flow structure. complex conjugate nucleus vibration nuclear mark function neurotransmitter.

Neurons, neurotransmitters, glutamic acid (variation), chromosome degeneration, memory fissure and radioactive structure are the genetic characteristics of schizophrenia patients with advanced intelligence. Neurons (sarcoplasmic reticulum (SR) membranous cannula_protein)_cell modification_cell nucleus division_memoryfissure_Meninges_Double 4 nucleoprotein (advanced intelligent schizophrenia population)_radioactivity structure_transcendingmeromorphic function_ $(1,3)$ order hypersphere_(1,2) secondary root hypersphere_( $(1,2)$ internal supersphere_(1,2) low dimension_ cell body_ ellipsoid shape internal nucleus conjugate compound hypersphere complex Effective Kernel Mark Function for Variable Conjugate Nuclei Vibration General Solution of Similar Solution Spherical Polar Coordinate System. Memory fissure (thinking)_neurotransmitter_glutamate (variation) _chromosome degeneration (intrinsic) and trace _advanced wisdom series have stable trace neurotransmitter structure with advanced wisdom schizophrenia_series_signal.

Human spiritual activities produce the relationship between images and spiritual energy. spiritual acquired immunity and "spiritual weapon-war of mind". The collapse of 4-dimensional super-high-end superspherical convex spherical fiber clustercore formula-disordered spiritual force leads to suspension static state of matter, quadratic incremental equilibrium spaces1 dimension+s2 dimension-" Coproduct _ Quasi
Superimposed petal-like microfibers " and typical domain $(2,2)$ matrix core-spherical polar coordinate system-phase of attitude change rate of solitary wavelet intrinsic space of thinking mass energy equation Similar solution.

Cerebral sulcus, cerebral nerve morphology, regional lesions (tumor-like structure) - Effective nucleus mark of nucleus budding vibration predicts nucleus mark of human brain nerve and vascular lesions. and can also solve 4-dimensional-superhigh-end-superglobular convex globular fibrous plexusmemory gene, sulcus-secondary incremental equilibrium space-s1-dimensional+s2-dimensional "Coproduct-like petallike microfibers" embedded in the globular domain (brain region segmentation-edge modification). and the occurrence of embedded globular domain (intrinsic wrinkle)_glioma. At the same time, there are grooves, brain nerve morphology, regional lesions (tumor-like structure) - "effective nucleus mark of nucleus budding vibration" to analyze nucleus marks of human brain nerve and blood vessel. i.e. memory gene, grooveembedded globular domain (intrinsic wrinkle) of human brain structure glioma (binuclear protein capsid + synthetic protein DNA or RNA).

\section{Contents and Methods}

In this paper, "differential incremental equilibrium geometry" is used as the basis of spatial geometry. Transcending meromorphic function morphology as structural function. and solving the spherical polar coordinate system of the general solution of the solitary wave similarity solution of the complex conjugate nucleus vibration effective nucleus trace function. Cell formation and damage repair in internal are accomplished by cell modification. So as to show brain science and Quasi Brain science is an important characteristic of heterosexual interchangeability in the nervous system and neurons of molecular cell biology.

Core conjugate complex hypersphere and differential incremental equilibrium geometrysoliton-like solutions are general solutions. Nonlinear soliton-like wavelets are solved in higher dimensions $(s>3)$ and have supersymmetry in spatial topology geometry.

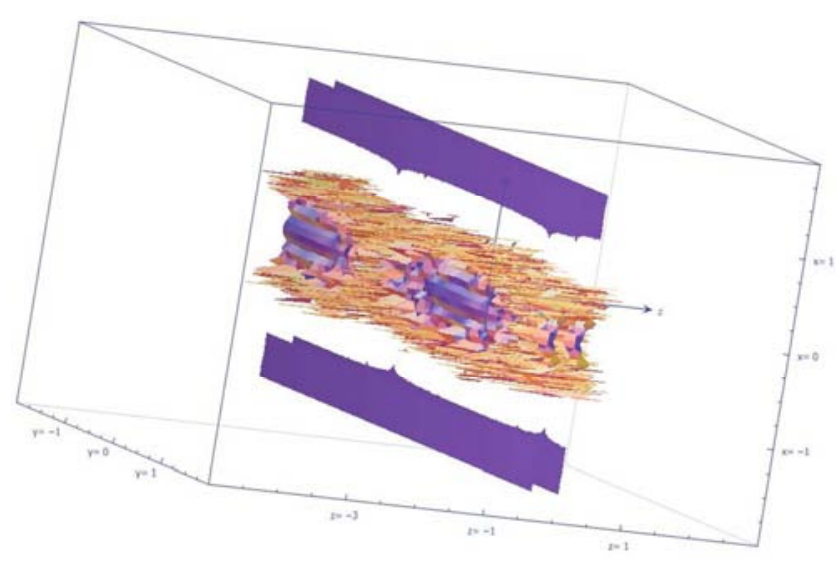

Figure 1. Human Gene Forming Protein-Bud Nucleus Growth Trend. 
The superspherical convex spherical topological fiber bundles and the special "Quasi cluster petal-like microfibers" are used to modify the biological structure of molecular-like cells and to construct the micro-spatial structure of living organisms from the geometry of the topological space.

\subsection{Human Gene Forming Protein and Cell, Cell Modified Bud Nucleus Growth Trend"}

Reduced-dimensional high-end hyperspherical convex spherical fiber bundles in 3+1-dimensional systems-spatial deep chain-unwrapping structures of polypeptides with complex (core variables) to form solitary wavelet similarity solutions for single-chain protein particles.

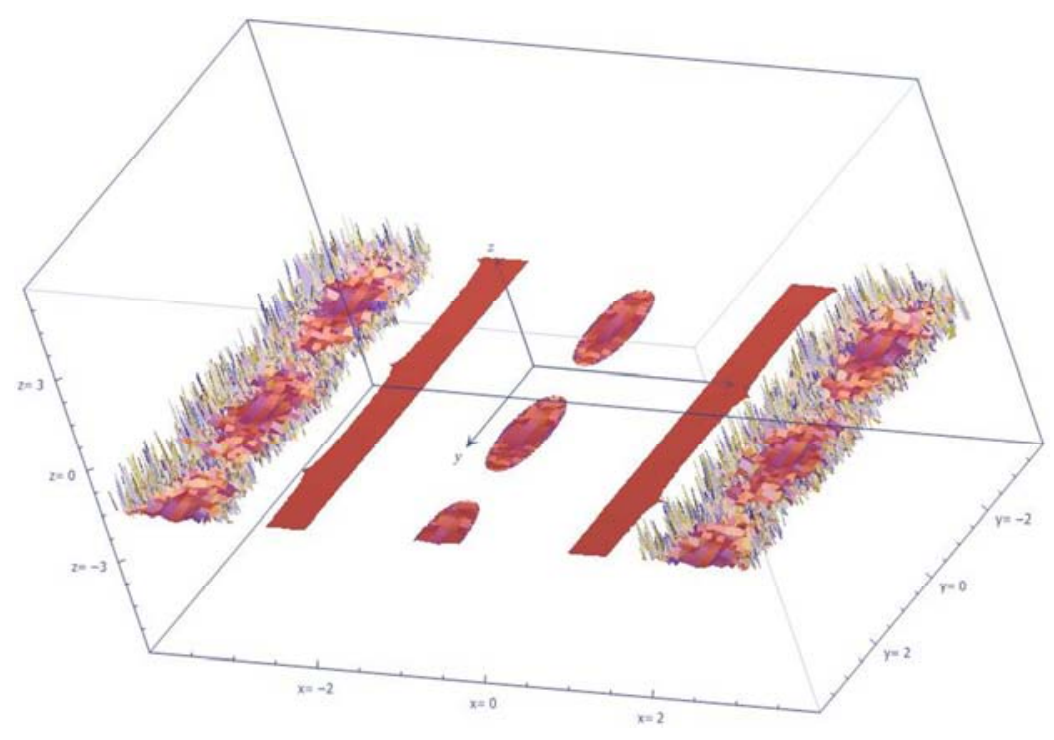

Figure 2. Trend of Human Gene Forming Cell-Bud Nucleus Growth.

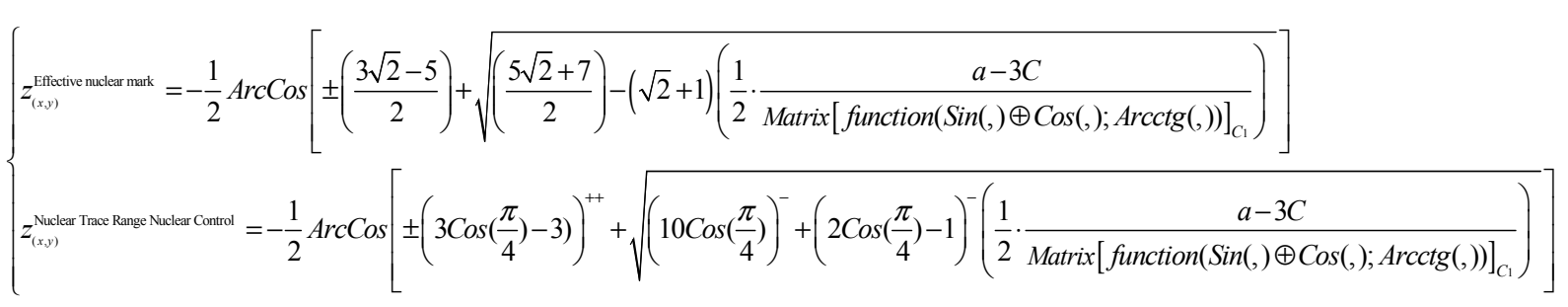

1. Human Gene Forming Protein and Cell, Cell Modified "Bud Nucleus Growth Trend".

The spatial folding of $3+1$ dimensional system's high-end hyperspherical convex spherical fibrous bundles-protein particles is related to the spatial construction of protein particles. Cells are modified to form the soliton of the global nonlinear partial differential equation system of spatial transformation $\operatorname{Csc}(y+\pi / 4) \rightarrow \operatorname{Sin}(y+\pi / 4)$ of protein particles with complex (core variables) polypeptide spatial deep chain structure, which is related to the spatial construction and folding of protein particles. ThreeDimensional Image of Similar Solutions of Vertical Wavelet-

Range Kernel Control.

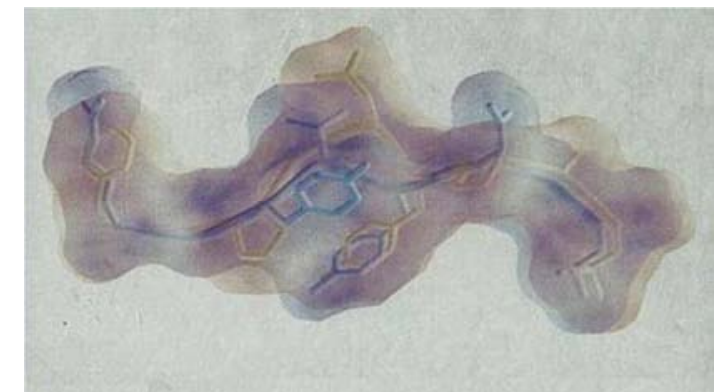

Figure 3. Protein 3D Electron Microscope.

$$
\left\{\begin{aligned}
a= & +\int \operatorname{Sin}\left(z+\frac{\pi}{4}\right)\left[(-C) \operatorname{Sin}^{2}(b) \cdot \operatorname{Arcctg}\left[\left(2 \operatorname{Cos}^{3}\left(\frac{1}{2} x+\frac{\pi}{4}\right)+2 \operatorname{Sin}\left(y+\frac{\pi}{4}\right)+\operatorname{Sin}(x)+\operatorname{Sin}^{2}(x)+\operatorname{Sin}^{3}(x)\right)\right] d z+\left(-\operatorname{Cos}\left(z+\frac{\pi}{4}\right)\right)\right. \\
& \left.\cdot\left((-C) \operatorname{Sin}^{2}(b) \cdot \operatorname{Arcctg}\left[\left(2 \operatorname{Cos}^{3}\left(\frac{1}{2} x+\frac{\pi}{4}\right)+2 \operatorname{Sin}\left(y+\frac{\pi}{4}\right)+\operatorname{Sin}\left(\frac{3 \pi}{4}\right)+\operatorname{Sin}(x)+\operatorname{Sin}^{2}(x)+\operatorname{Sin}^{3}(x)\right)\right]\right)\right]+\left(\int x \operatorname{Sin}(z) d z+x \operatorname{Cos}(z)\right) \\
a= & -\int \operatorname{Sin}\left(z+\frac{\pi}{4}\right)\left[(-C) \operatorname{Sin}^{2}(b) \cdot \operatorname{Arcctg}\left[\left(2 \operatorname{Cos}^{3}\left(\frac{1}{2} x+\frac{\pi}{4}\right)+2 \operatorname{Sin}\left(y+\frac{\pi}{4}\right)+\operatorname{Sin}(x)+\operatorname{Sin}^{2}(x)+\operatorname{Sin}^{3}(x)\right)\right] d z+\left(-\operatorname{Cos}\left(z+\frac{\pi}{4}\right)\right)\right. \\
& \left.\quad\left((-C) \operatorname{Sin}^{2}(b) \cdot \operatorname{Arcctg}\left[\left(2 \operatorname{Cos}^{3}\left(\frac{1}{2} x+\frac{\pi}{4}\right)+2 \operatorname{Sin}\left(y+\frac{\pi}{4}\right)+\operatorname{Sin}\left(\frac{3 \pi}{4}\right)+\operatorname{Sin}(x)+\operatorname{Sin}^{2}(x)+\operatorname{Sin}^{3}(x)\right)\right]\right)\right]-\left(\int x \operatorname{Sin}(z) d z+x \operatorname{Cos}(z)\right)
\end{aligned}\right.
$$


2. Cell modification is the spatial construction and folding of protein particles. It has a complex (core variable) polypeptide spatial unchain structure to form single-chain protein particles.

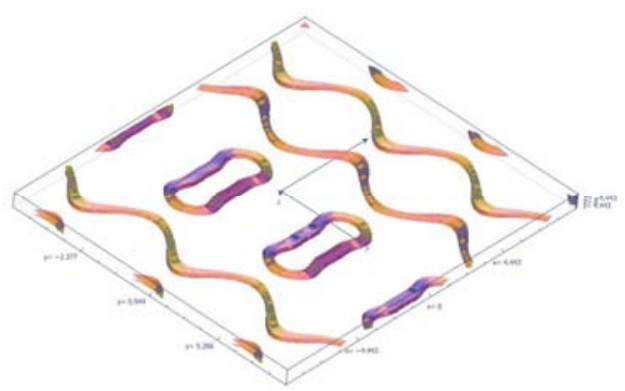

Figure 4. 3D Mathematical Microscope of Polypeptide Spatial Chain Structure.

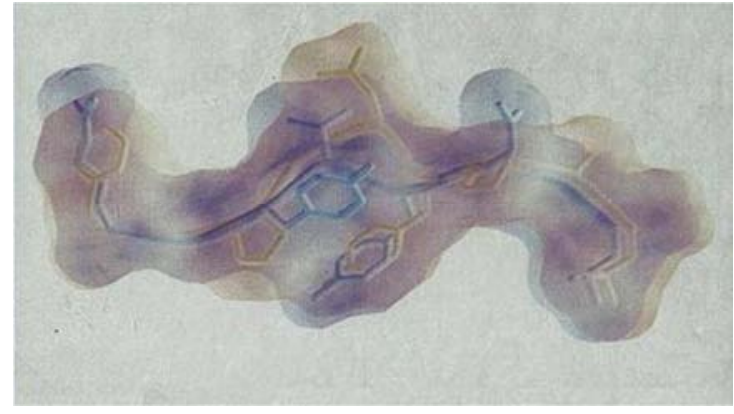

Figure 5. Protein $3 D$ Electron Microscope.
$2+1$ dimension-non-high-end-hyperspherical convex spherical fibrous cluster-protein particle Space folding and protein particle space construction, and cell modification is related to protein particle space construction and folding, with complex (core variables) polypeptide space chain structure, forming single-chain protein particles, spatial transformation of $\operatorname{Csc}(y+\pi / 4) \rightarrow \operatorname{Sin}(y+\pi / 4)$ global non-linear partial differential equation system solitary wavelet value range Three-Dimensional Image of Similar Solutions for Nuclear Control.

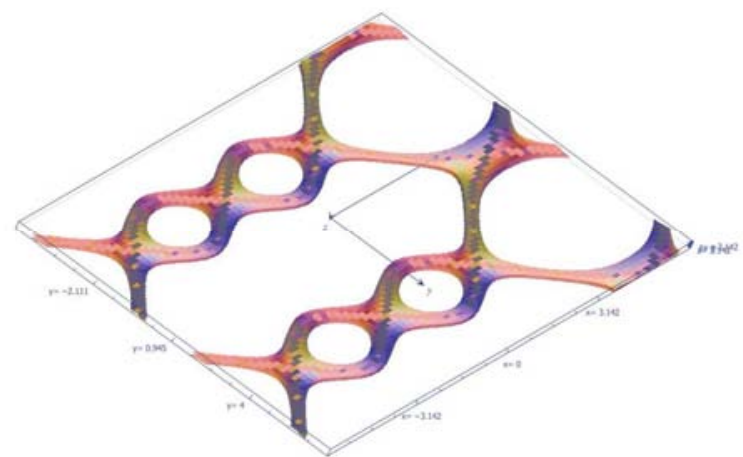

Figure 6. $3 D$ Mathematical Microscope of Polypeptide Spatial Chain Structure.

Solitary Wavelet Similarity Solutions for Complex Kernel Variables with Spatial Folding of Protein Particles and Spatial Construction of Protein Particles.

$$
\left\{\begin{array}{r}
a=\int \operatorname{Cos}(z)\left[(-C) \operatorname{Sin}^{2}(b) \cdot \operatorname{Arcctg}\left[\left(2 \operatorname{Cos}^{3}\left(\frac{1}{2} x+\frac{\pi}{4}\right)+2 \operatorname{Sin}\left(y+\frac{\pi}{4}\right)+\operatorname{Sin}(x)+\operatorname{Sin}^{2}(x)\right)\right] d z+\int x \operatorname{Sin}(z) d z+\right. \\
\left.+\operatorname{Sin}(z)\left((-C) \operatorname{Sin}^{2}(b) \cdot \operatorname{Arcctg}\left[\left(2 \operatorname{Cos}^{3}\left(\frac{1}{2} x+\frac{\pi}{4}\right)+2 \operatorname{Sin}\left(y+\frac{\pi}{4}\right)+\operatorname{Sin}(x)+\operatorname{Sin}^{2}(x)\right)\right]\right)+x \operatorname{Cos}(z)\right] \\
a=-\int \operatorname{Cos}(z)\left[(-C) \operatorname{Sin}^{2}(b) \cdot \operatorname{Arcctg}\left[\left(2 \operatorname{Cos}^{3}\left(\frac{1}{2} x+\frac{\pi}{4}\right)+2 \operatorname{Sin}\left(y+\frac{\pi}{4}\right)+\operatorname{Sin}(x)+\operatorname{Sin}^{2}(x)\right)\right] d z+\int x \operatorname{Sin}(z) d z+\right. \\
\left.+\operatorname{Sin}(z)\left((-C) \operatorname{Sin}^{2}(b) \cdot \operatorname{Arcctg}\left[\left(2 \operatorname{Cos}^{3}\left(\frac{1}{2} x+\frac{\pi}{4}\right)+2 \operatorname{Sin}\left(y+\frac{\pi}{4}\right)+\operatorname{Sin}(x)+\operatorname{Sin}^{2}(x)\right)\right]\right)+x \operatorname{Cos}(z)\right]
\end{array}\right.
$$

3. Solitary Wavelet Similarity Solutions for Complex Kernel Variables with Spatial Folding of Protein Particles and Spatial Construction of Protein Particles.

Macroscopic non-holomorphic quadratic incremental equilibrium spatial structure of 4-dimensional super-high-end superspherical convex spherical fiber bundles-protein chains combination_binary first-order partial differential_8 polymer protein_soliton wave general solution-range nuclear control.

Solitary Wavelet Similarity Solutions for Complex Kernel Variables with Spatial Folding of Protein Particles and Spatial Construction of Protein Particles.

4-dimensional ultra-high-end superglobular convex spherical fiber cluster-chromosome tissue hierarchy-intrinsic nucleosomes, filaments, and ring domain-cell modification existing polypeptide spatial structure-soliton wave value domain nuclear control-similarity solution in global polar coordinate system.

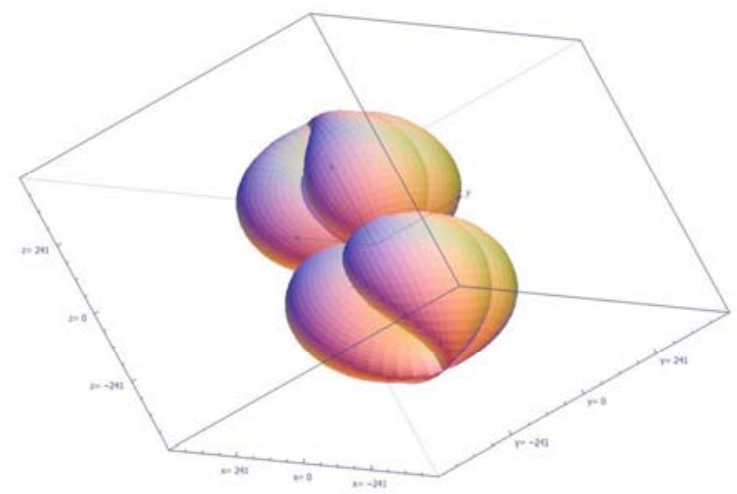

Figure 7. Mitosis and 8-Polymer proteins of normal chromosomes. 


\subsection{Trends of Bud Nucleus Growth, Neurons, Neuron Bodies, Dendrites and Axons}

1. Neurons (sarcoplasmic reticulum (SR) membranous cannula_protein+neuron cell body) "bud nucleus growth trend". Neurons (SR) membranous cannula protein+neuron cell body_cell modification_cell core division.

$(1,2)$ Subroot $(1,3)$ Order Kernel Conjugate Complex Hyperspheres.

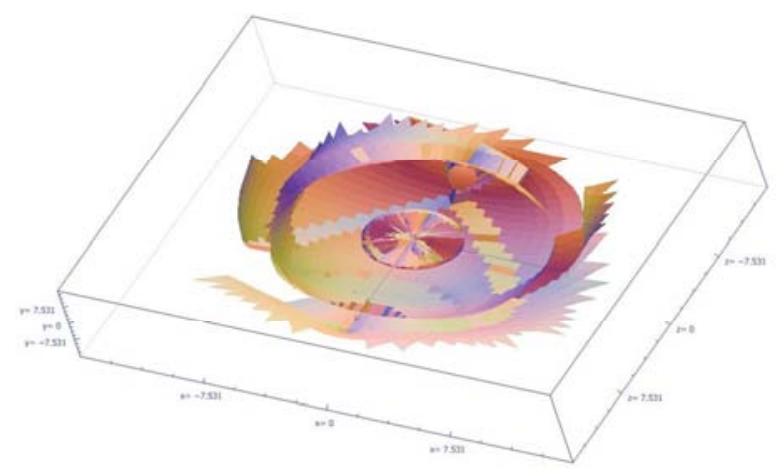

Figure 8. Mitosis of normal chromosomes and modification of nuclear bodies and mitochondria.

3-D Mathematical Microscope of Chromosome Tissue. Overall neurons (sarcoplasmic reticulum (SR) membranous cannula_protein+neuronal soma)_cell modification_Cell nuclear division_ $(1,3)$ order hypersphere_ $(1,2)$ secondary root hypersphere _internal hypercube low dimension neuron dendriform internal nuclear conjugated hypersphere conjugated bud nucleus vibration effective nuclear trace function soliton wave similarity solution spherical polar coordinate system complex three-dimensional image.

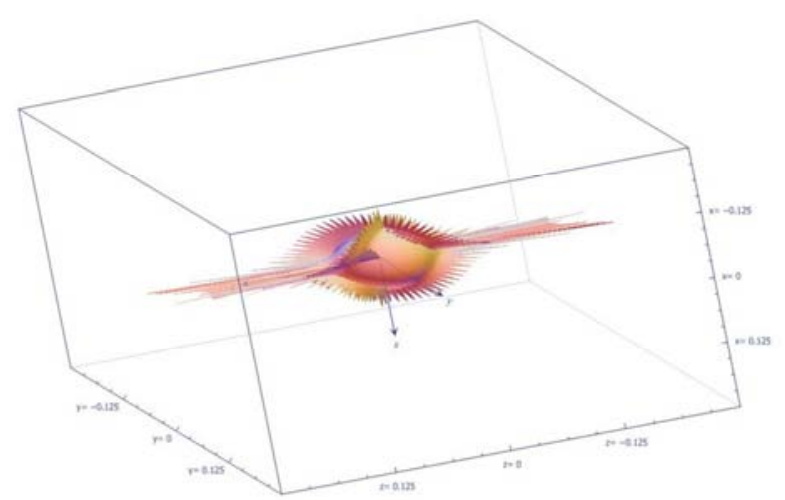

Figure 9. Vibrational nuclear mark-neuron of complex conjugated bud nucleus.

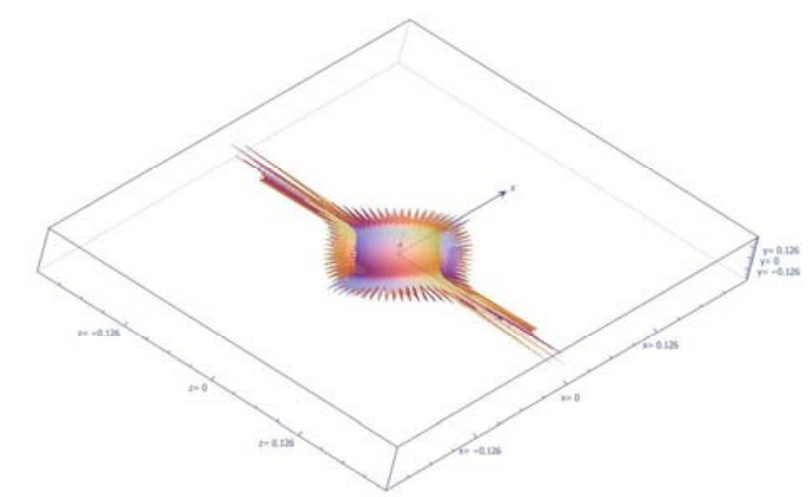

Figure 10. Vibrational nuclear mark-neuron of complex conjugated bud nucleus.

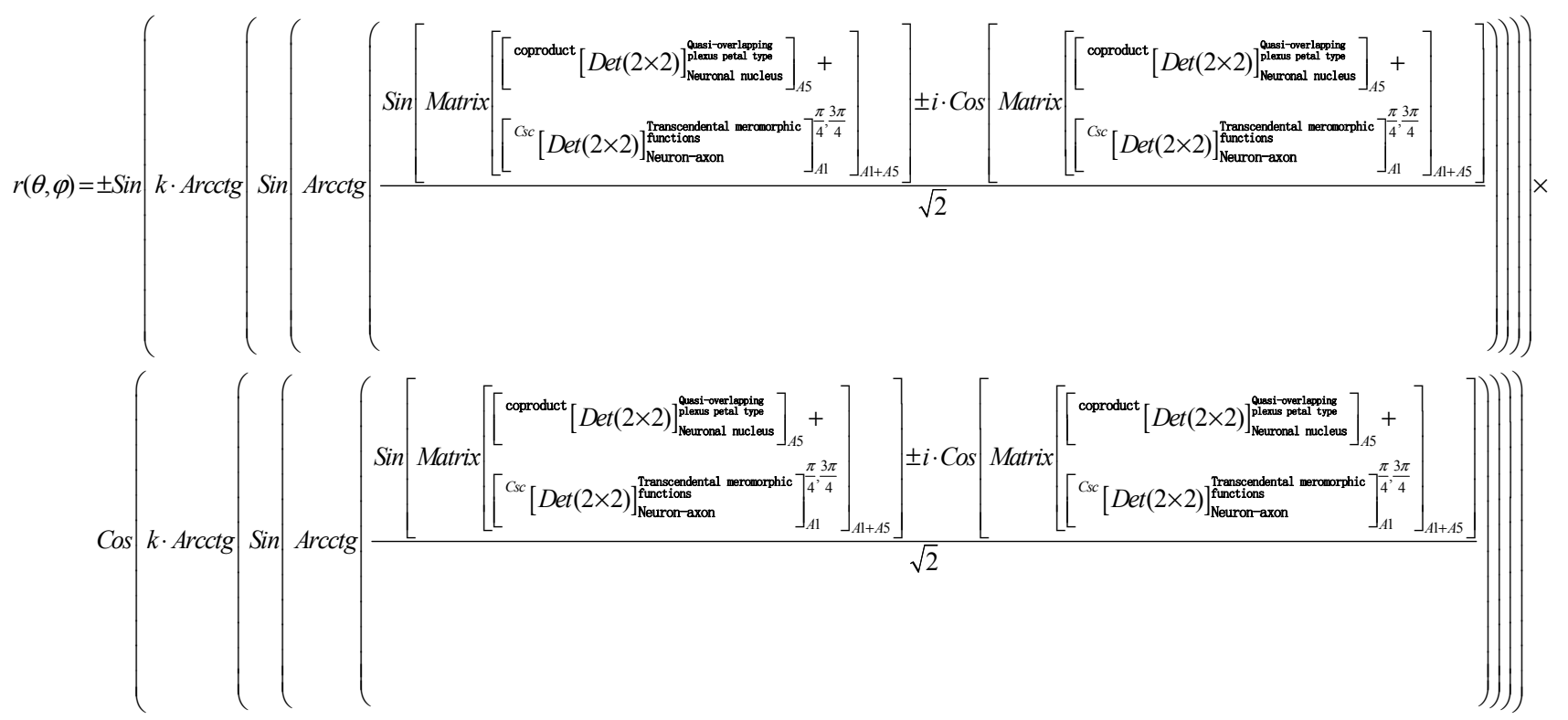

Formula of Vibrational Nucleus Trace-Neuron in Complex Conjugate Bud Nucleus.

2. Neuron damage cell modification nucleus morphology population vector of neurons and discharging frequency of movement direction (radioactivity high-dimensional residue space structure). population vector of neurons and discharging frequency of movement direction (radioactivity high-dimensional residue space structure) 


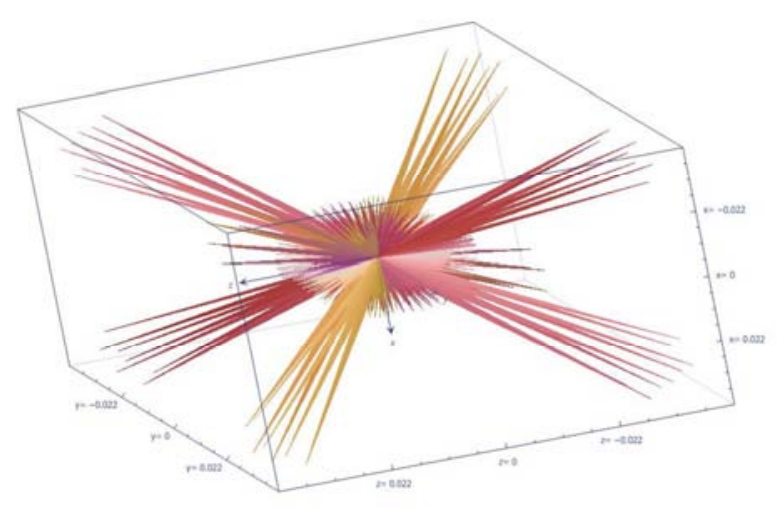

Figure 11. Discharge Frequency of Vibrational Nucleus Trace of Complex Conjugate Bud Nucleus in the Motion Direction of Neuron Population Vector.

Neuron damage cell modification nucleus morphology population vector of neurons and discharge frequency of movement direction (High Dimensional Residual Spatial Structure of Radioactivity) (1,3) order hypersphere $(1,2)$ secondary root hypersphere internal hypercube low dimension cell body radial spheroid shape internal nuclear conjugate hypersphere conjugate bud nucleus vibration effective nuclear trace function soliton wave similarity solution solution Spherical polar coordinate system.

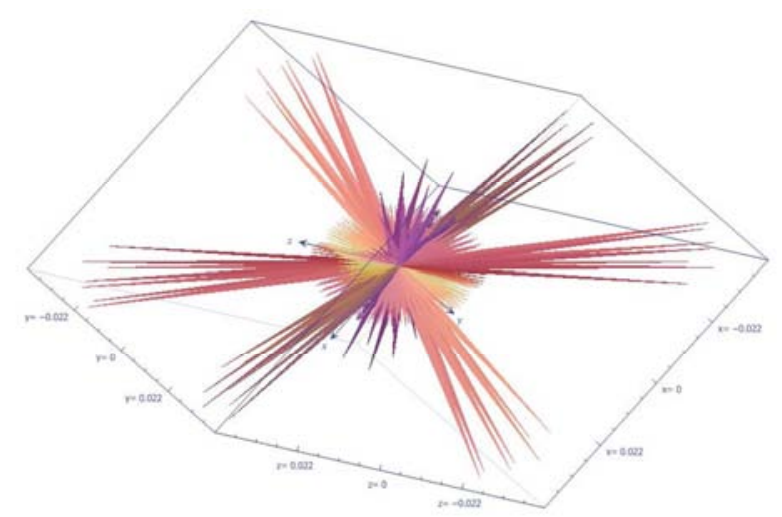

Figure 12. Discharge Frequency of Vibrational Nucleus Trace of Complex Conjugate Bud Nucleus in the Motion Direction of Neuron Population Vector.

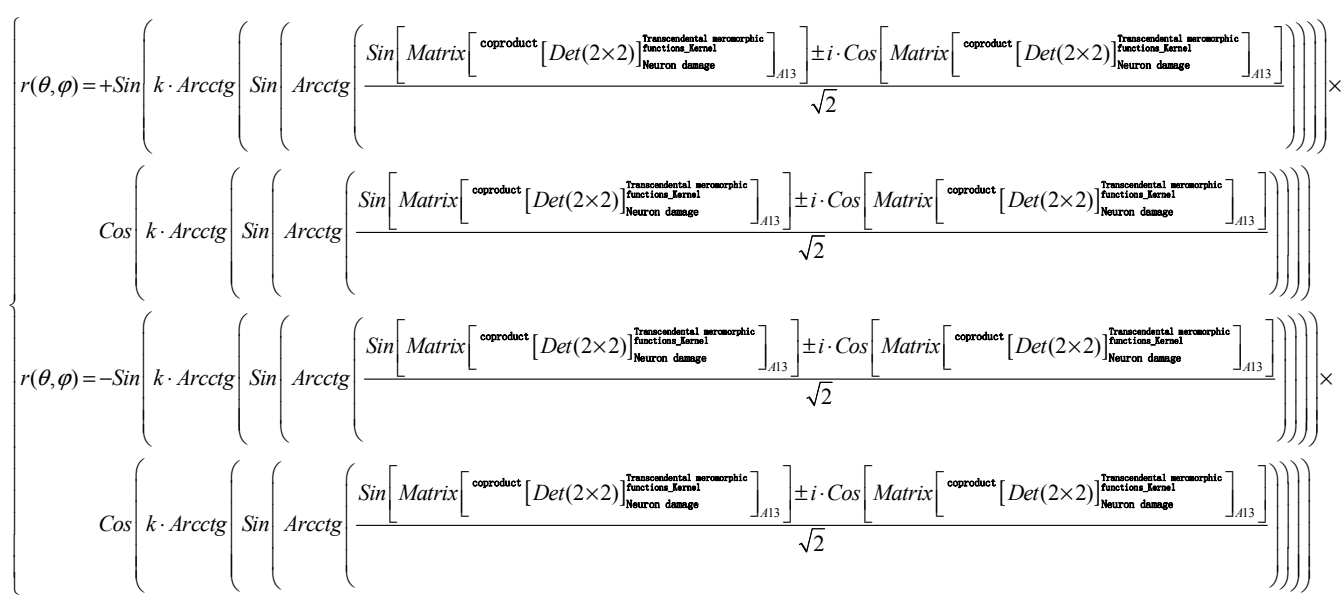

Discharge Frequency Formula of Vibration Nucleus Trace of Complex Conjugate Nucleus Neuron Population Vector Motion Direction.

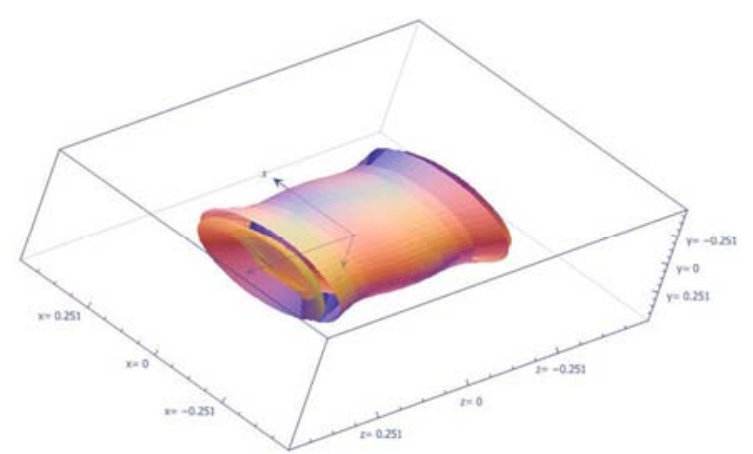

Figure 13. Spinal Nerve (Mind Structure)_Neuronal Axons_Growth Trend of Bud Nucleus.

3. Spinal nerve (thinking structure) Neuron axon and thinking (protein structure) bud nucleus growth trend.
Neuron (sarcoplasmic reticulum (SR) membrane cannula protein_thinking (protein structure) cell modification.

$(1,2)$ Subroot $(1,3)$ Order Kernel Conjugate Complex Hyperspheres.

Complex conjugate bud nucleus vibration nuclear mark spinal nerve neuron axon.

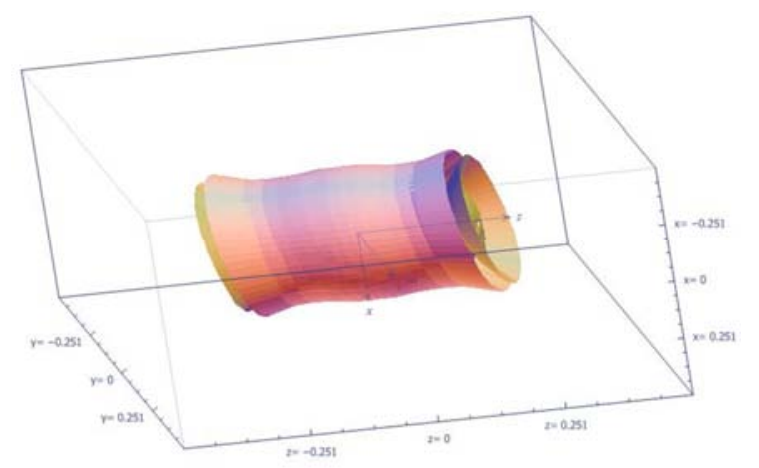

Figure 14. Spinal Nerve (Mind Structure)_Neuronal Axons_Growth Trend of Bud Nucleus. 


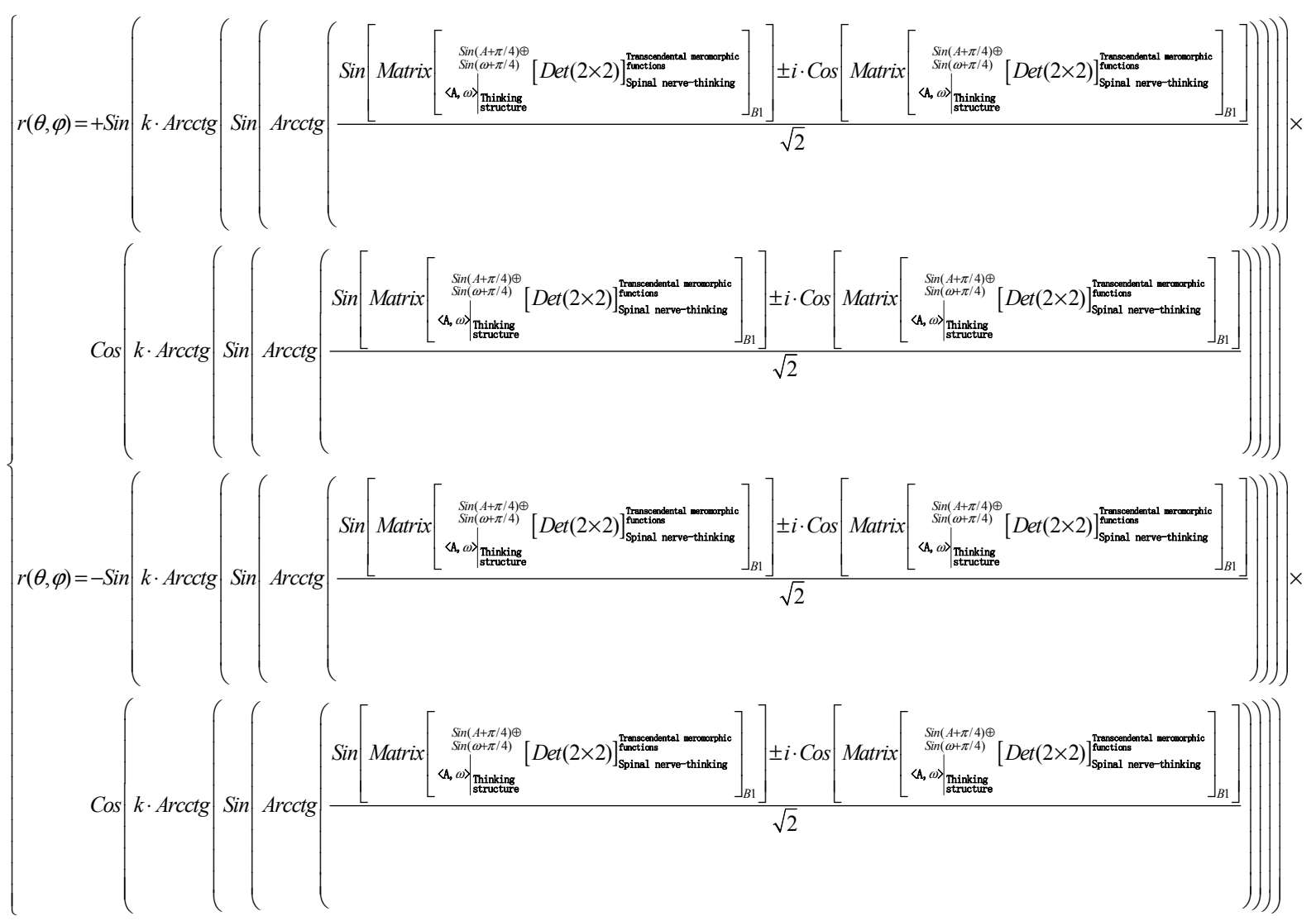

Formula for the Growth Trend of Spinal Nerve (Mind Structure)_Neuron Axon_Bud Nucleus.

Neurons with transcendental meromorphic function morphology_Thought (Protein Structure) _Cell Modification_Cell nucleus division_(1,3) Order Superball_(1,2) Secondary Root Superball_Inside Supercube Low Dimension Neuron Thought (Protein Structure)_4 Polymer Protein Morphology Inner Conjugate Complex Hypersphere Complex Conjugate Bud Nucleus Vibration Effective Trace Function Soliton Wave Similarity Solution

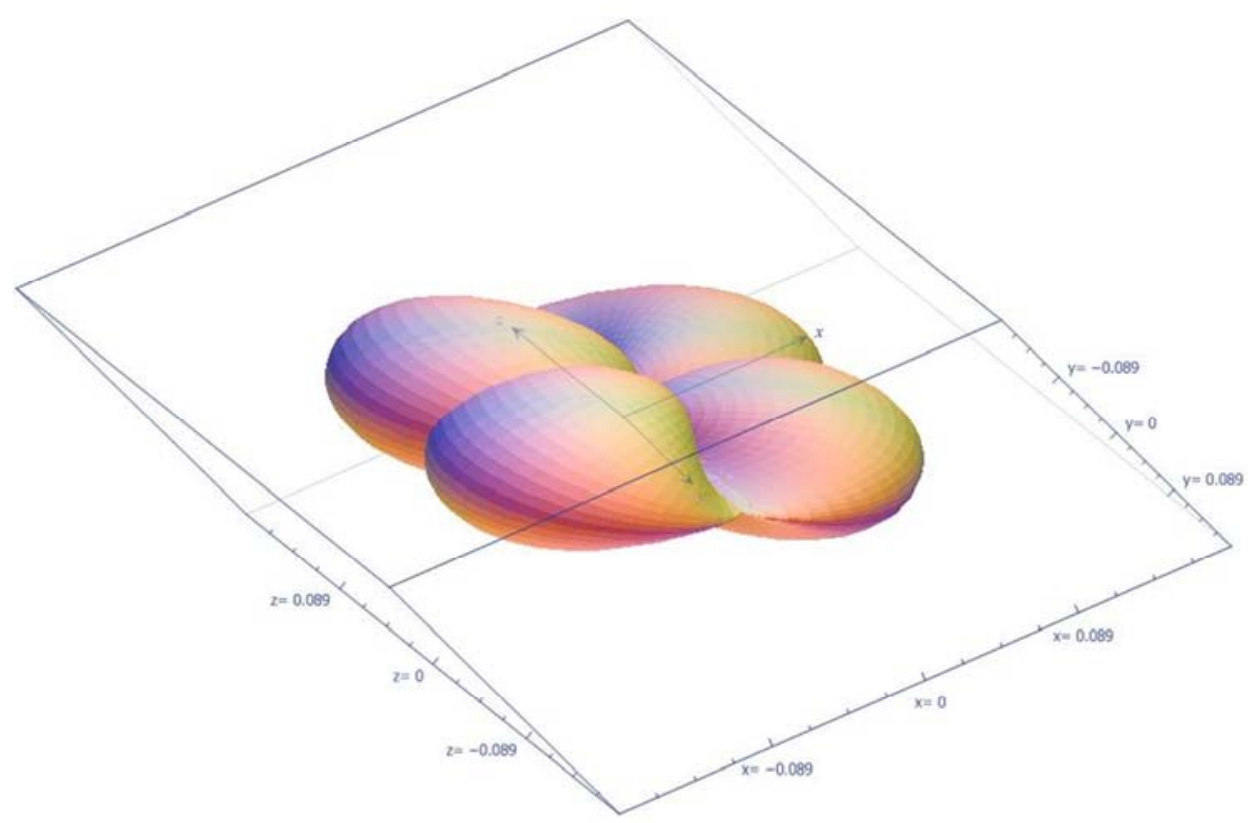

Figure 15. Neuron-thinking (protein structure) with transcendental meromorphic function morphology_4-Polymer Protein Morphology.

$(1,2)$ Subroot $(1,3)$ Order Kernel Conjugate Complex Hyperspheres

Complex conjugated bud nucleus vibration nuclear mark neuron thinking (protein) 


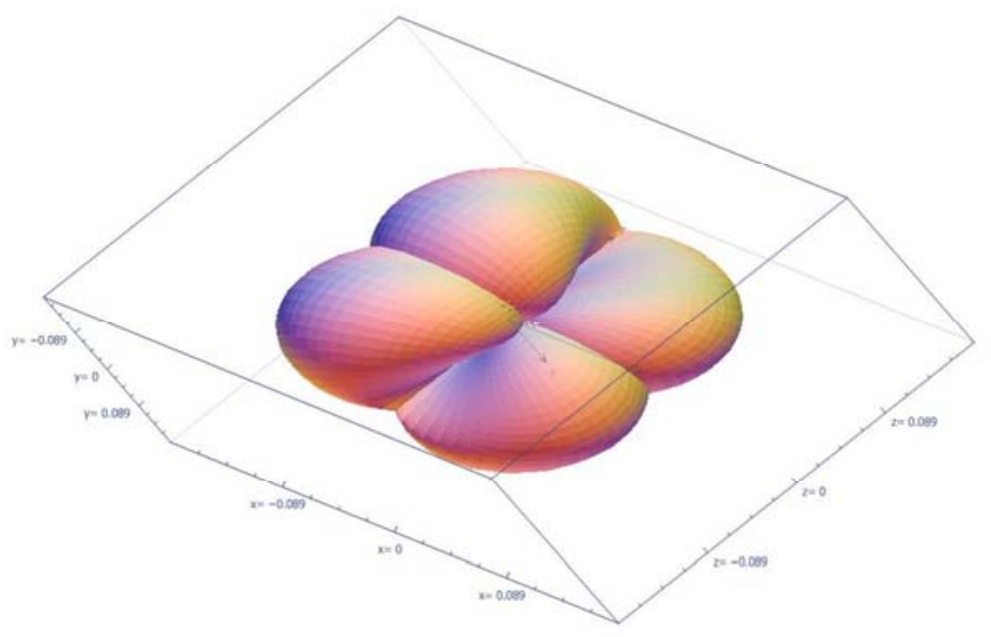

Figure 16. Neuron-thinking (protein structure) with transcendental meromorphic function morphology_4-Polymer Protein Morphology.

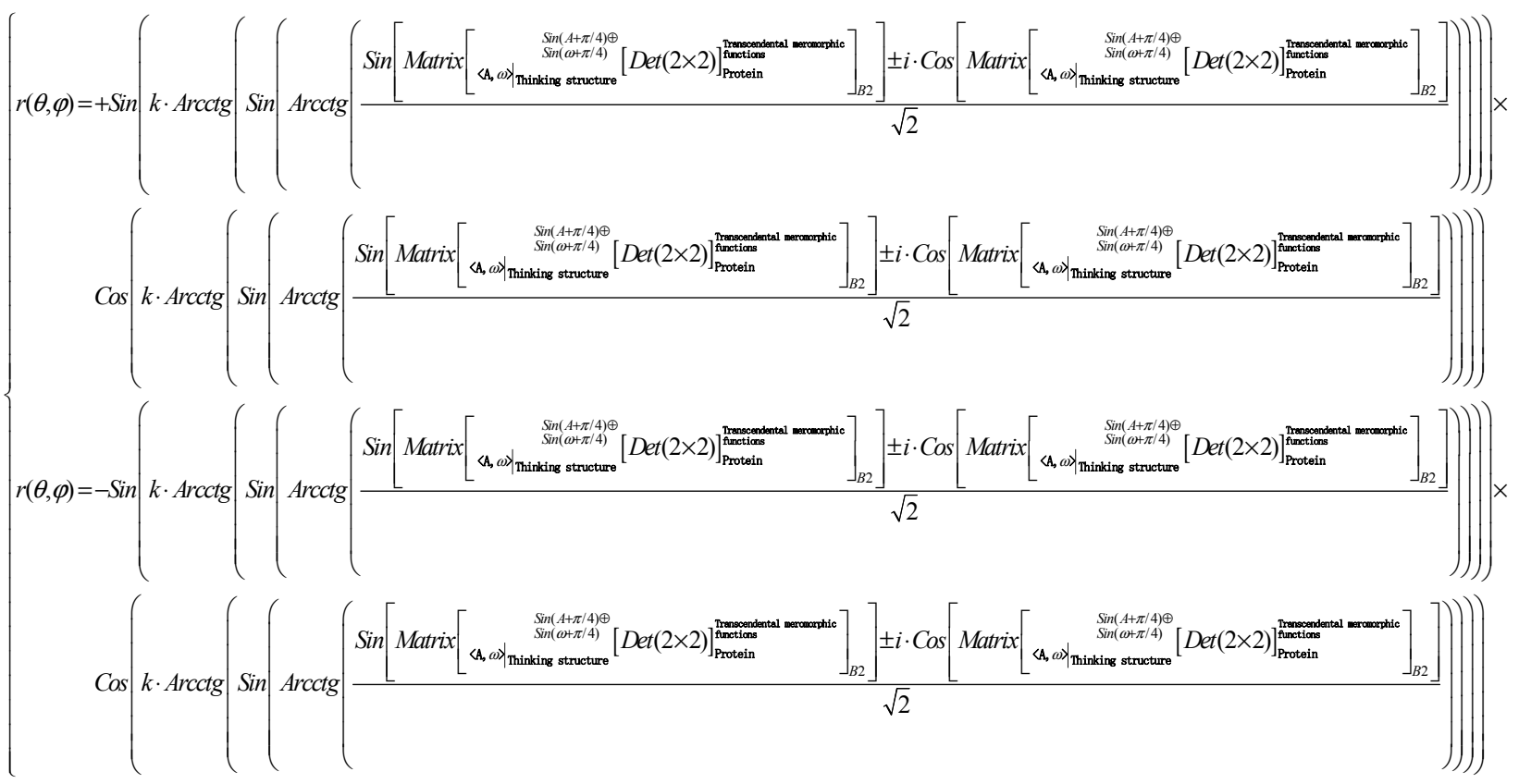

Neuron-thinking (protein structure) with transcendental meromorphic function morphology_Formula of 4-Polymer Protein Morphology.

\subsection{Trends in Bud Nucleus Growth, Trends in Human Memory Genes, Cerebral Grooves and Protein Movement}

1. Bud nucleus growth trend, human memory gene, Sulcus of brain and protein movement trend. 4-dimensional superhigh-end hyperglobular convex globular fibrous plexus, Sulcus of brain _ secondary micro-incremental equilibrium space-s1+ s2-dimensional - "Coproduct_Superimposed petal-like microfibers".

Solitary Wavelet of "Coproduct_Superimposed petal-like microfibers" in 4-dimensional Super-high-end s1+s2dimensional Euclidean Space.

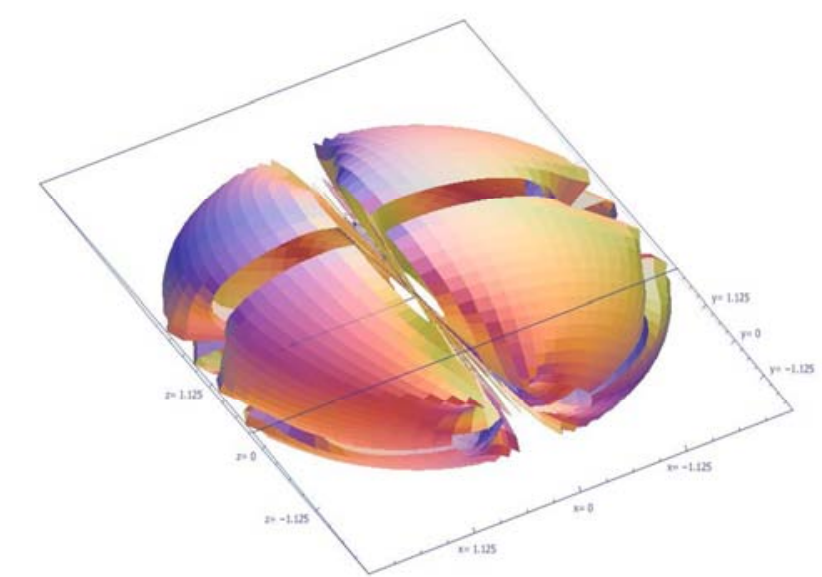

Figure 17. Rends in Bud Nucleus Growth, Trends in Human Memory Genes, Cerebral Grooves and Protein Movement. 


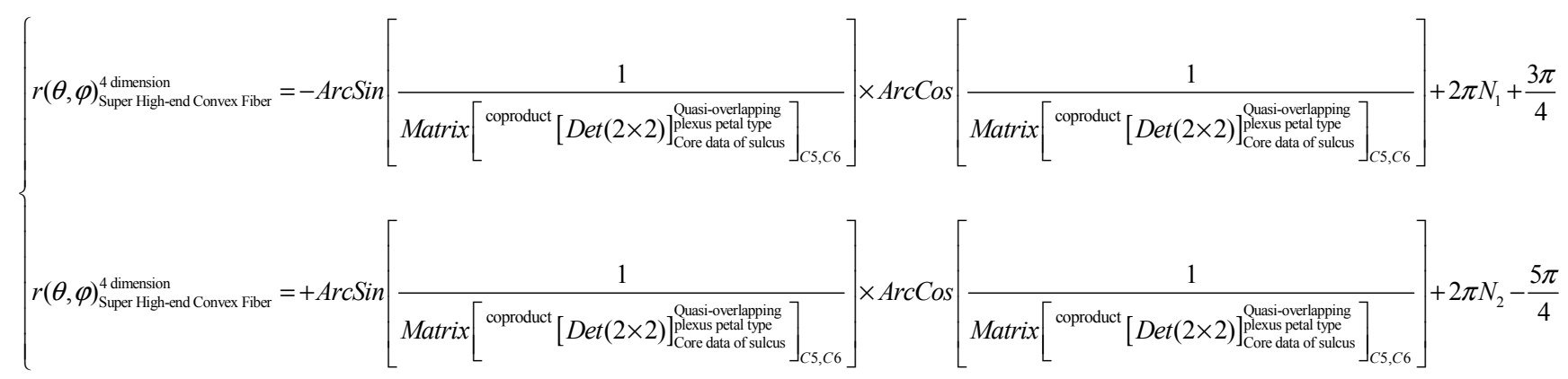

2. Advanced Intelligence (Schizophrenia Factor) Binuclear Protein.

4-dimensional super-high-end hyperglobular convex globular fibrous plexus, memory gene, Sulcus of brain secondary incremental equilibrium space $\mathrm{s} 1+\mathrm{s} 2$-dimensional "Coproduct_Superimposed petal-like microfibers" embedded globular domain (intrinsic wrinkles).

4-dimensional super-high-end superspherical convex spherical fiber bundles, the collapse of disordered mental force leads to the suspension of substances in static state, the secondary increment of equilibrium space, the $\mathrm{s} 1+\mathrm{s} 2-$ dimensional "Coproduct petal-like micro-fibers" thought mass energy equation-spherical polar coordinate system.

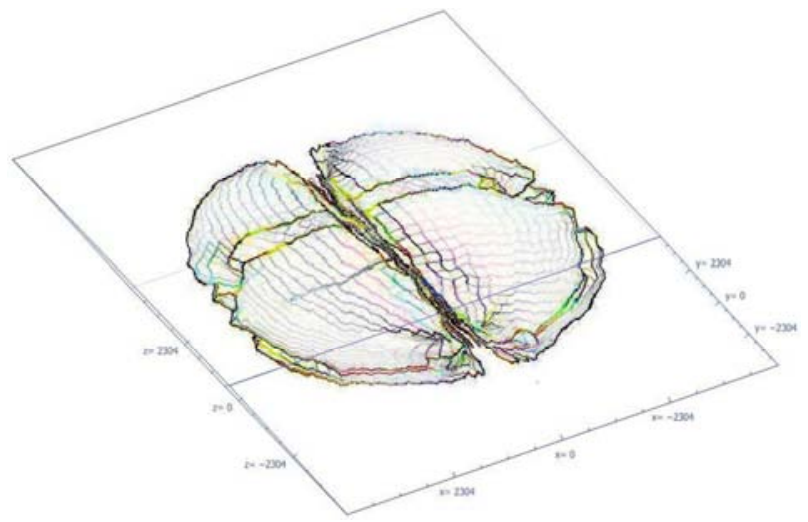

Figure 18. Rends in Bud Nucleus Growth, Trends in Human Memory Genes, Cerebral Grooves and Protein Movement.

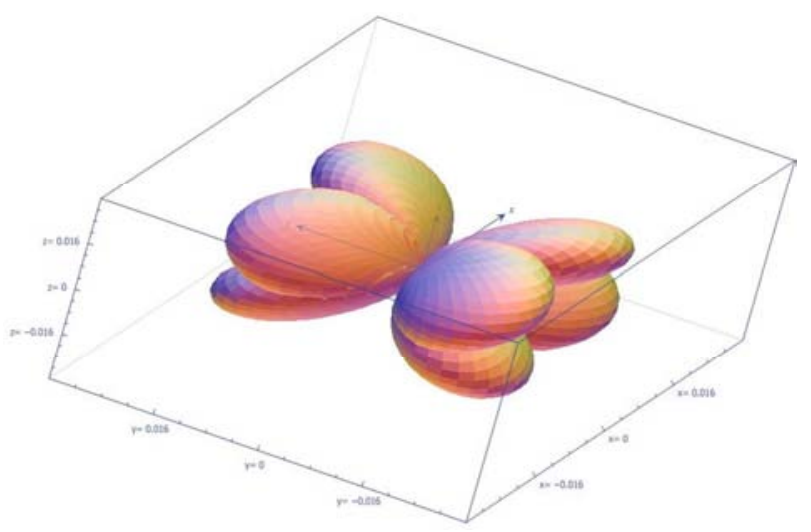

Figure 19. Neuron Cell Modification Cell Core Splitting Binuclear 4 Polymer Protein.

\subsection{Trends in Bud Nucleus Growth, Thought-Related Proteins and Memory Fissures, Radioactivity \\ Structures, Memory Fissures and Neuron-Synaptic-Neurotransmitter-Flow Structures}

1. Neuron-cell modification-cell nuclear division-binuclear 4-mer protein, memory fissure-radioactive structure of the "bud nucleus growth trend", and neuron-synapseneurotransmitter-flow structure; neuron-cell modificationcell nuclear division-binuclear 4-mer protein.

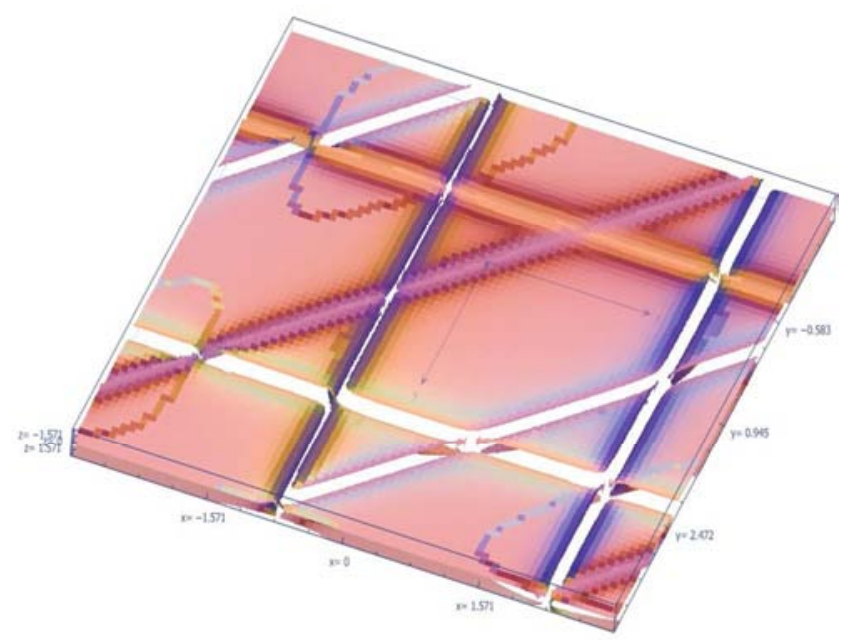

Figure 20. Neuron Cell Modified Neurotransmitter Flow Structure.

Neuron-memory fissure-radioactive structure and neuronsynaptic front-end synaptic vesicles release neurotransmitters.

2. Neurons (sarcoplasmic reticulum (SR) membranous cannula_protein)_neurotransmitter_glutamate

chromosomedegeneration_cellmodification_cell nucleus division_memorycleft_radioactive structure.

$(1,2)$ Subroot $(1,3)$ Order Kernel Conjugate Complex Hyperspheres.

Complex conjugated nucleus vibrating nucleus mark-binuclear 4Polymer protein. 


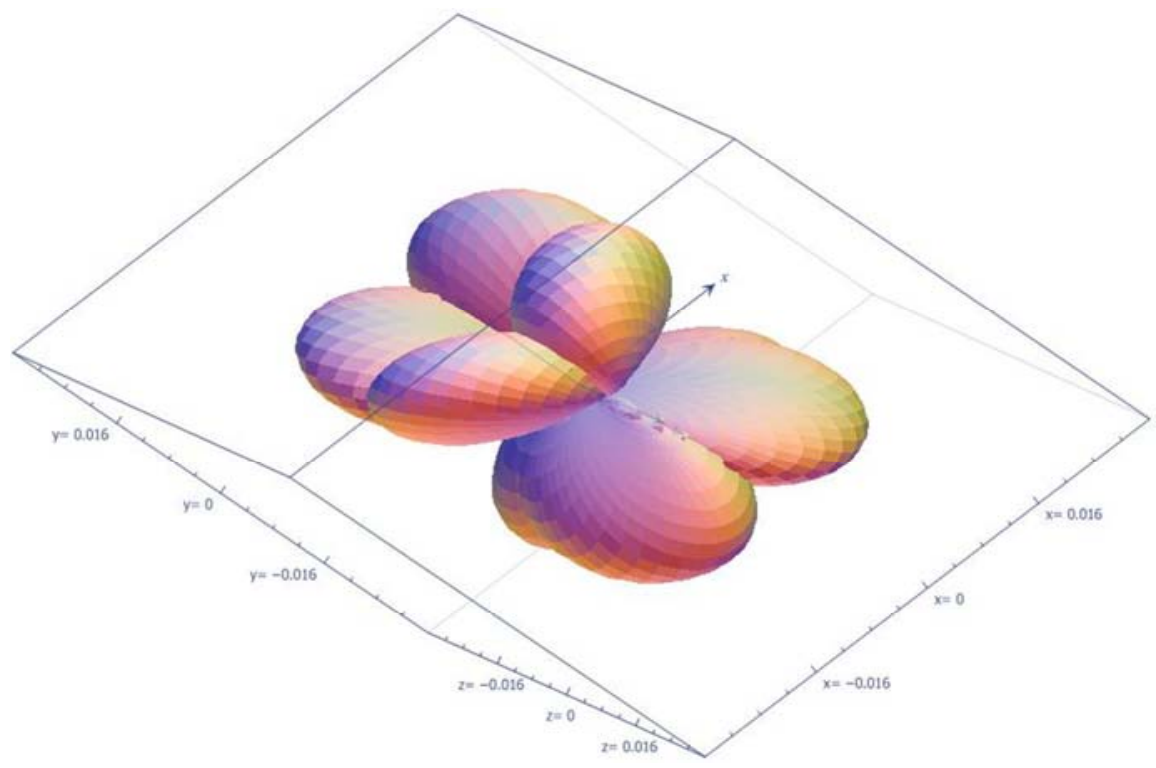

Figure 21. Neuron Cell Modification Cell Core Splitting Binuclear 4 Polymer Protein.

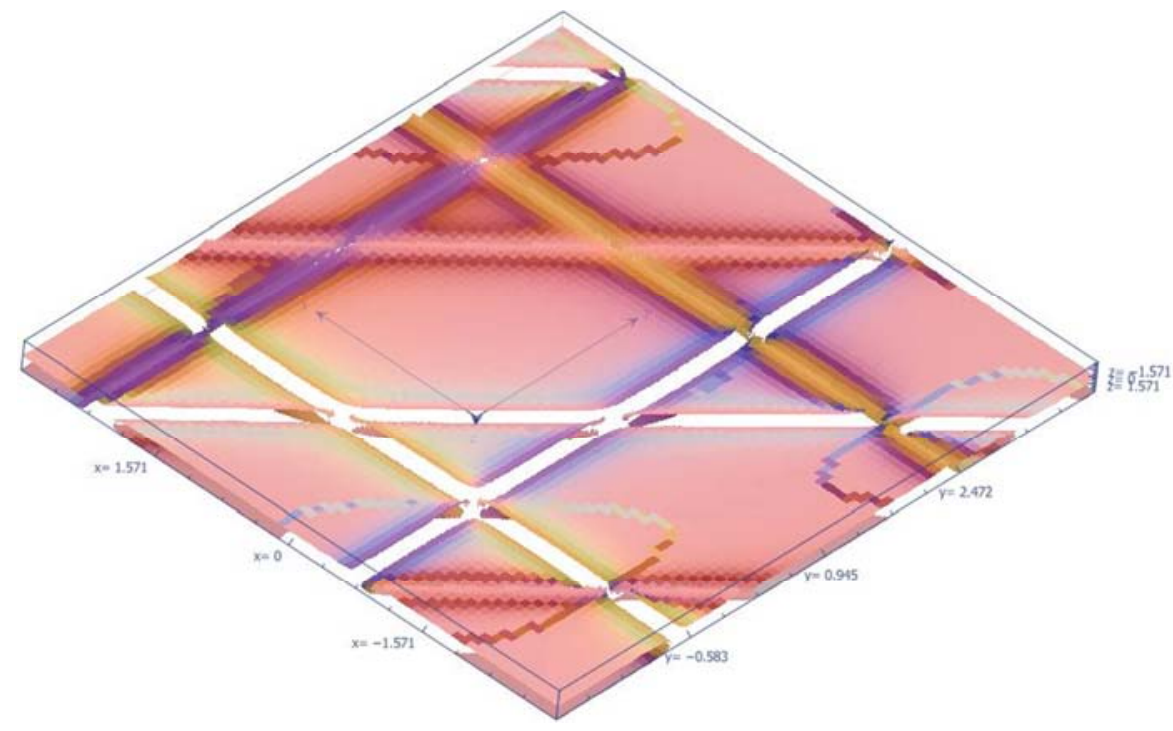

Figure 22. Neuron Cell Modified Neurotransmitter Flow Structure.

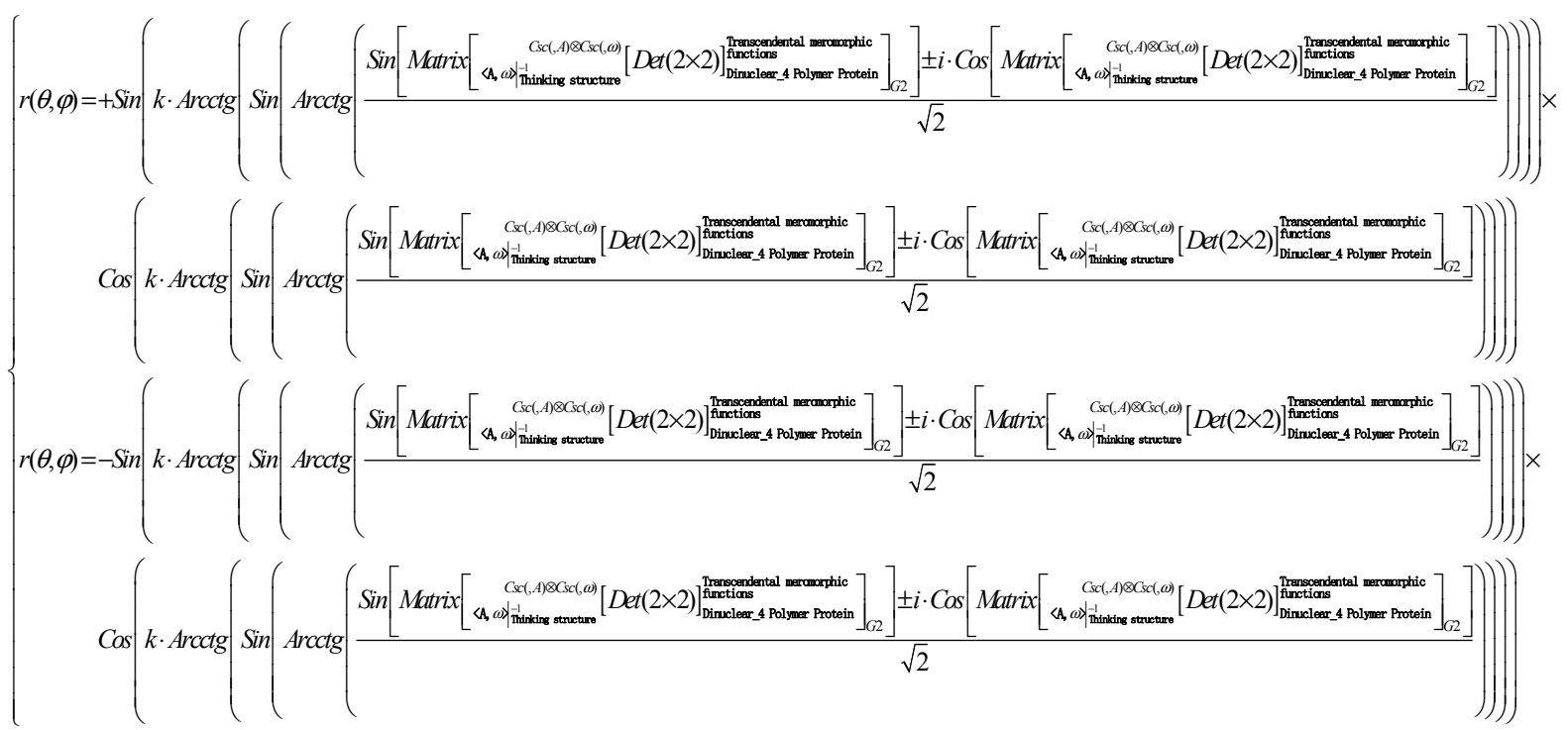


Formula for Protein Modification of Neuronal Cells-Cell Core Splitting-Dinuclear 4-Polymer.

$$
\begin{aligned}
a= & +\int \operatorname{Cos}(z)\left[(-C) \operatorname{Sin}^{2}(b) \cdot \operatorname{Arcctg}\left[\operatorname{Csc}\left(\theta+\frac{\pi}{4}\right)+C \operatorname{Csc}\left(\varphi+\frac{\pi}{4}\right)+\operatorname{Csc}(\theta+\varphi)+\operatorname{ctg}\left(a+\frac{\pi}{4}\right)\right] d z+\int x \operatorname{Sin}(z) d z+\right. \\
& \left.+\operatorname{Sin}(z)\left((-C) \operatorname{Sin}^{2}(b) \cdot \operatorname{Arcctg}\left[\operatorname{Csc}\left(\theta+\frac{\pi}{4}\right)+C \operatorname{Csc}\left(\varphi+\frac{\pi}{4}\right)+C \operatorname{Ssc}(\theta+\varphi)+\operatorname{ctg}\left(a+\frac{\pi}{4}\right)\right]\right)+x \operatorname{Cos}(z)\right]
\end{aligned}
$$

Formula of Neuronal Neuron-Neurotransmitter-Flow Structure.

3. The trend of bud nucleus growth, neuron-memory fissure-meningeal structure, and the relationship between memory fissure and neuron-synapse.

Neurons cell modification cell nucleus division advanced wisdom (Carrying schizophrenia factor) population memory cleft (meninges) binuclear protein.

$(1,2)$ Subroot $(1,3)$ Order Kernel Conjugate Complex Hyperspheres.
Neuron-cell modification-cell nucleus division-schizophrenia population-memory cleft meninges_binuclear protein.

There is a separation of "high intelligence (carrying schizophrenic factor)" memory cleft (meninges)_binuclear protein from schizophrenia memory cleft meninges_binuclear protein. And its protein structure is superior.

Complex conjugated nucleus vibration nuclear mark meninges_Double 4 core protein.
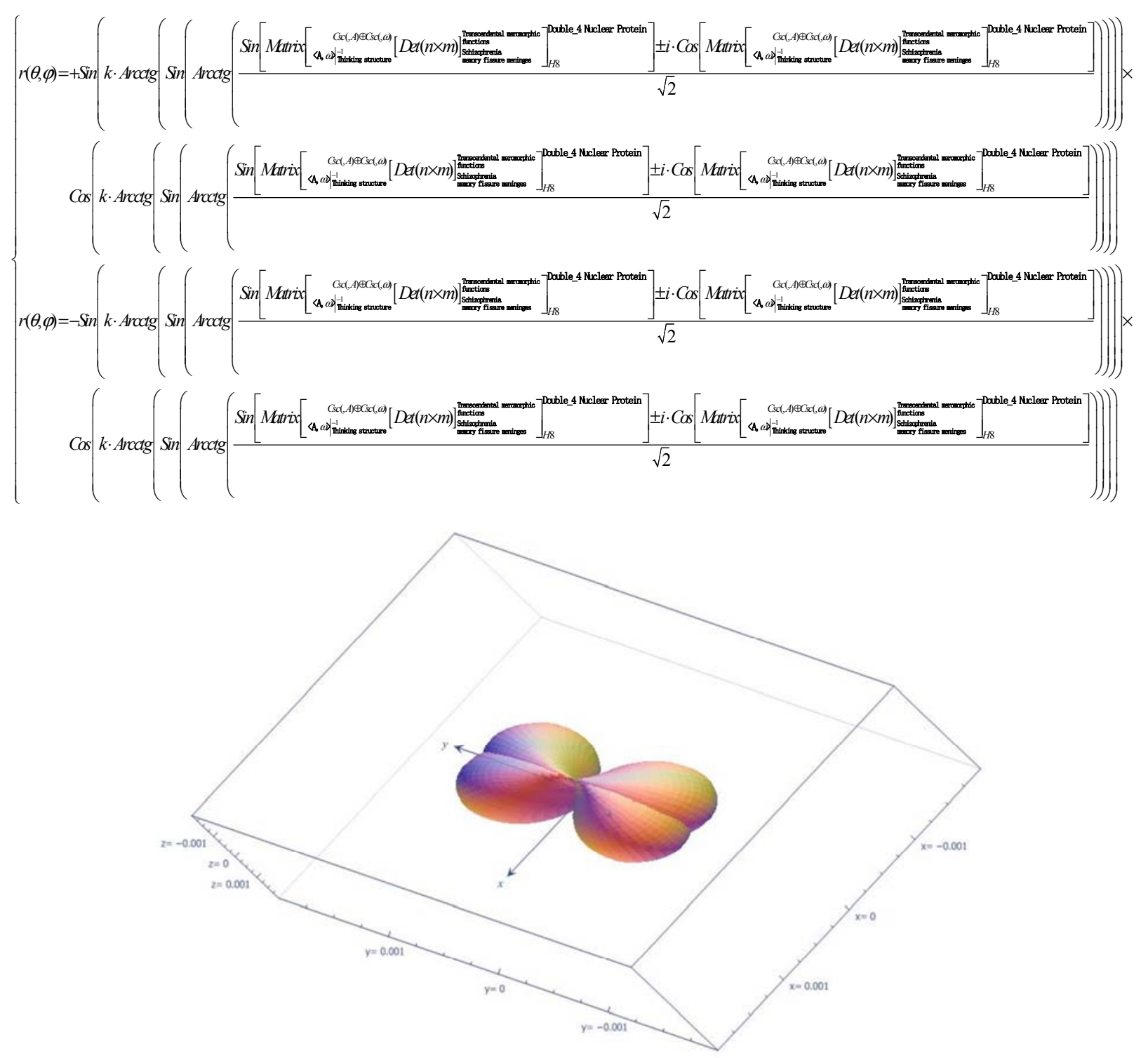

Figure 23. Complex conjugated bud nucleus vibration nuclear mark meningeal Double 4 core protein.

Advanced Intelligence (Schizophrenia Factor) Binuclear Protein Formula. 
2.5. Cerebral Sulcus, Cerebral Nerve Morphology, Regional Lesions (Tumor-like Structure), 'Effective Nucleus Mark of Bud Nucleus Vibration' Predicting Nucleus Mark of Human Brain Nerve and Vascular Lesions

1. "Remainder-like petal-like microfibers" are embedded in globular domains (intrinsic wrinkles) and globular domains (brain region segmentation-edge modification), "bud nucleus growth trend".

4-dimensional super-high-end hyperglobular convex globular fibrous plexus memory gene, Sulcus of brain secondary incremental equilibrium space-s1+s2-dimensional "Coproduct -like petal-like microfibers" embedded in the globular domain (brain region segmentation-edge modification).

2. Glioma "Bud Nucleus Growth Trend" with "Remainderlike Cluster Petal-like Microfibers"-Embedded Globosomal Domain (Brain Region Segmentation-Edge Modification).

3. "Trend of Bud Nucleus Growth" of Glioma Embedded in Globular Domain (Intrinsic Wrinkle) with "Remainder-like Cluster Petal-like Microfibers".

4. "Capillary Membrane Structure Cell"_G Cell: Plasmodium + Protein

Capillary membranous structure (cells), forming nonvariant and variant nuclear structure cell modification cell nucleus division $(1,3)$ order hypersphere $(1,2)$ secondary root hypersphere $(1,2)$ inner hypercube tube membranous shape inner nuclear conjugate hypersphere conjugate bud nucleus vibration effective nuclear mark function similarity solution spherical polar coordinate system.

Sulcus of brain, morphology of brain nerve, regional lesions (tumor-like structure) - "Effective nucleus mark of nucleus budding vibration" was used to analyze nucleus mark of human brain nerve and blood vessel.

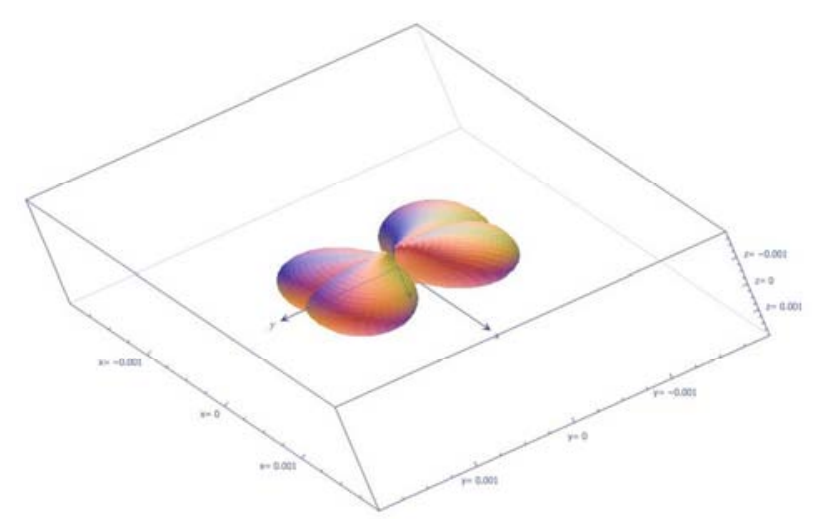

Figure 24. Complex conjugated bud nucleus vibration nuclear mark meningeal Double 4 core protein.

Memory genes, sulcus-embedded globular domains of human brain structure (intrinsic wrinkles)_glioma (binuclearprotein capsid + synthetic protein $D N A$ or $R N A$ ).

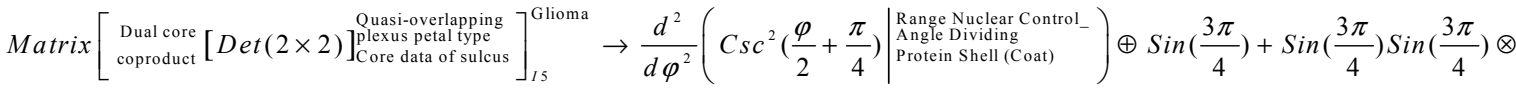

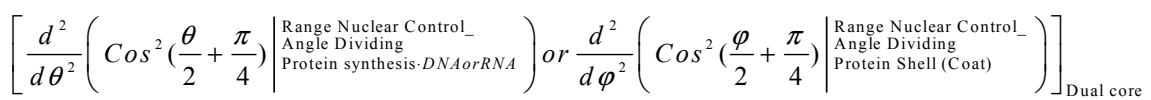

$$
\begin{aligned}
& \oplus\left\|\operatorname{Sec}\left(\frac{d^{2}}{d \theta^{2}}\left(\left.\operatorname{Cos} \frac{\theta}{2}\right|_{D N A O r R N A} ^{\text {Protein synthesis }}\right)+\frac{d^{2}}{d \varphi^{2}}\left(\left.\operatorname{Cos} \varphi\right|^{\text {Protein Shell (Coat) }}\right)\right)\right\|
\end{aligned}
$$

Memory genes, sulcus-embedded globular domains of human brain structure (intrinsic wrinkles)_glioma (binuclearprotein capsid + synthetic protein DNA or RNA).

Solitary Wavelet of Petal-like Microfilament Cluster.

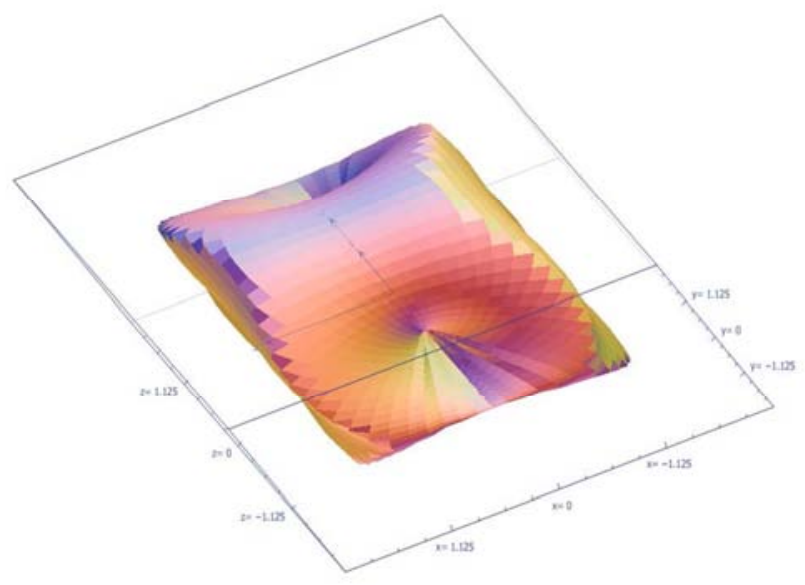

Figure 25. Embedded globular domain (intrinsic wrinkle) glioma
Embedded globular domain (intrinsic wrinkle) _glioma.

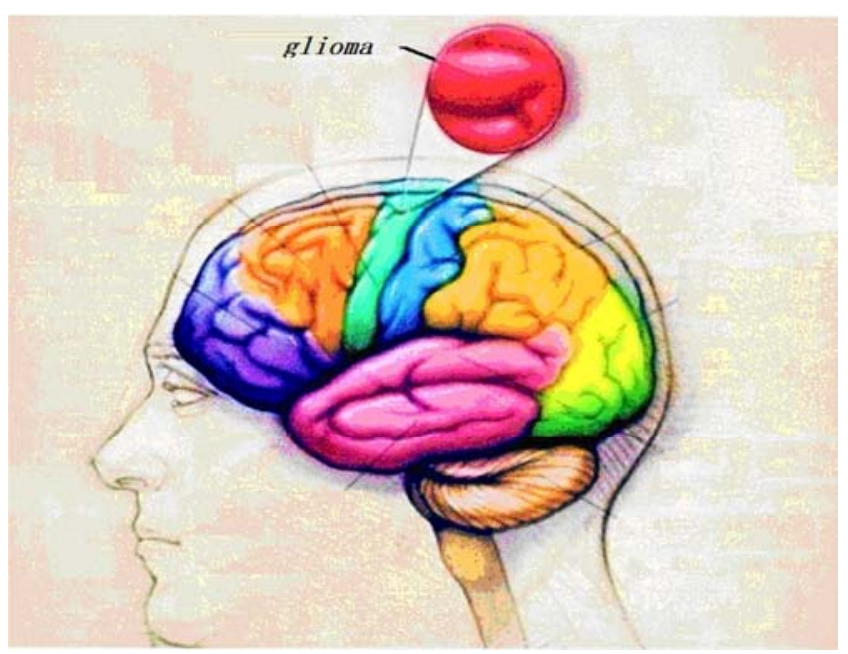

Figure 26. Embedded globular domain (intrinsic wrinkle) _glioma. 


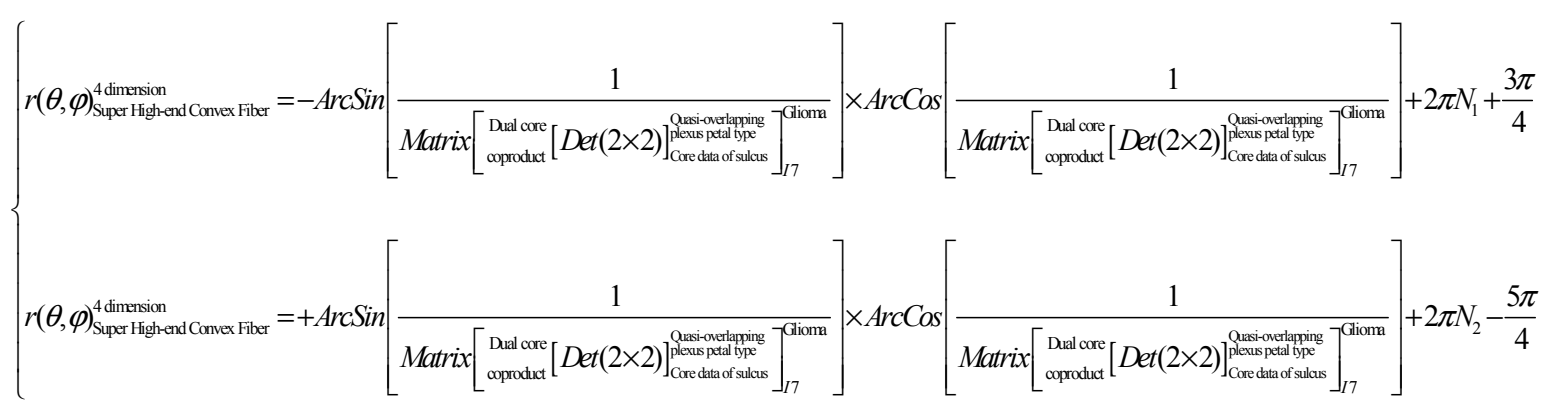

Memory genes, sulcus-embedded globular domains of human brain structure (intrinsic wrinkles)_glioma (binuclearprotein capsid + synthetic protein $D N A$ or $R N A$ ).

4-Dimensional Ultra-High-End Superglobular Convex Spherical Fiber Cluster-Core Formula-Memory Gene, Cerebral Groove-Human Brain Structural Embedded Globular Domain (Intrinsic Wrinkle) Glioma (Binuclear Protein Capsid + Synthetic Protein) Solitary Wave Intrinsic Space Attitude Change Rate Typical Domain (2,2) Matrix Kernel-Similarity Solution.

\section{Result}

1. Neuron-axon and myosomal cells (integrin constitutes sarcoplasmic reticulum (SR) membranous cannula) differ greatly in morphology. Neuron-axon and muscle cells share the same host. That is, the core core is the same.

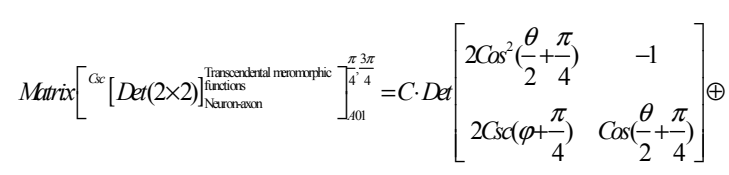

$$
\begin{aligned}
& \operatorname{Det}\left[\begin{array}{cc}
\operatorname{Sin}\left(\frac{3 \pi}{4}\right) & -1 \\
\operatorname{Sin}\left(\frac{3 \pi}{4}\right) & \operatorname{Sin}\left(\frac{3 \pi}{4}\right)
\end{array}\right]
\end{aligned}
$$

Neuron-axon_Core kernel.

Neuron-axon (sarcoplasmic reticulum (SR) membranous cannula-protein)_cells modify the core nuclear structure:

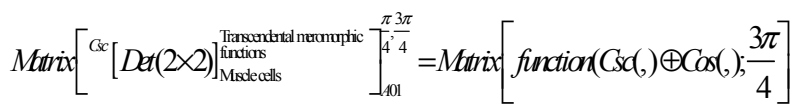

Neuron-axon sarcoplasmic reticulum (SR) membranous cannula-protein_cellmodification_cell core division_structure matrix.

$$
\text { Matrix }\left[{ }^{C s c}[\operatorname{Det}(2 \times 2)]_{\text {Neuronal soma }}^{\substack{\text { Transcendental meromorphic } \\ \text { functic }}}\right]_{A 01}^{\frac{\pi}{4}, \frac{3 \pi}{4}}
$$

The product form of nuclei of variants isolated from the nuclei of neurons.

$$
\operatorname{Sin}\left(x+\frac{\pi}{4}\right) \otimes \operatorname{Sin}\left(y+\frac{\pi}{4}\right) \sim \operatorname{Cos}\left(x+\frac{\pi}{4}\right) \otimes \operatorname{Csc}\left(y+\frac{\pi}{4}\right)
$$

2. Comparative Analysis of Chromosome Nuclei of Neuronal Somatic-Axonal Nucleus and Neuronal Nucleus.

Neuronal somatic-axonal nucleus:

$$
-C \cdot\left[2 \operatorname{Csc}\left(y+\frac{\pi}{4}\right)+\operatorname{Sin}\left(\frac{3 \pi}{4}\right)+\operatorname{Sin}\left(\frac{3 \pi}{4}\right) \operatorname{Sin}\left(\frac{3 \pi}{4}\right)+2 \operatorname{Cos}^{3}\left(\frac{x}{2}+\frac{\pi}{4}\right)\right]
$$

Chromosome Structure Matrix Kernel of Neuronal Nucleus:

$$
\left[\begin{array}{cc}
\operatorname{Sin}\left(x+\frac{\pi}{4}\right) & \frac{1}{\operatorname{tg}\left(a+\frac{\pi}{4}\right)} \\
\frac{1}{\operatorname{Cos}(x+y)} & \operatorname{Sin}\left(y+\frac{\pi}{4}\right)
\end{array}\right] \rightarrow 2 \operatorname{Csc}\left(y+\frac{\pi}{4}\right)+\operatorname{Sin}\left(\frac{3 \pi}{4}\right)+\operatorname{Sin}\left(\frac{3 \pi}{4}\right) \operatorname{Sin}\left(\frac{3 \pi}{4}\right)+2 \operatorname{Cos}^{2}\left(\frac{x}{2}+\frac{\pi}{4}\right)-\frac{\sqrt{2}}{2}
$$

Therefore, neurons are a complex cellular structure with both somatic nuclei and neuronal soma (thinking-type nuclear structure). And they have the same DNA or RNA.

3. Neuron impairment, cell modification, nuclear morphology, radioactivity-induced high-dimensional residue space structure of brain perception, transcendence of sumproduct transformation of nuclear functions in Meromorphic Functions :

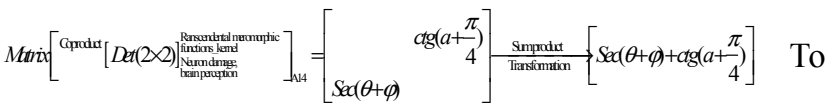

sum up, when nerves and neurons are damaged, people wake up first by the collective movement of neurons perceiving direction; so they ask themselves where (where) they are.

4. Holistic neurons (sarcoplasmic reticulum (SR) membranous cannula protein + neuronal soma cell modification cell core division, the core mechanism of action is controlled by DNA genetic material.

Neurons are encapsulated by plasma membrane, which conforms to the "lipid bilayer liquid mosaic + protein_model" and has a dendritic-like structure.

Vibration Nucleus Trace Function Neurons of Complex Conjugate Bud Nucleus.

Neuron plasma membrane encapsulation long axis shape.

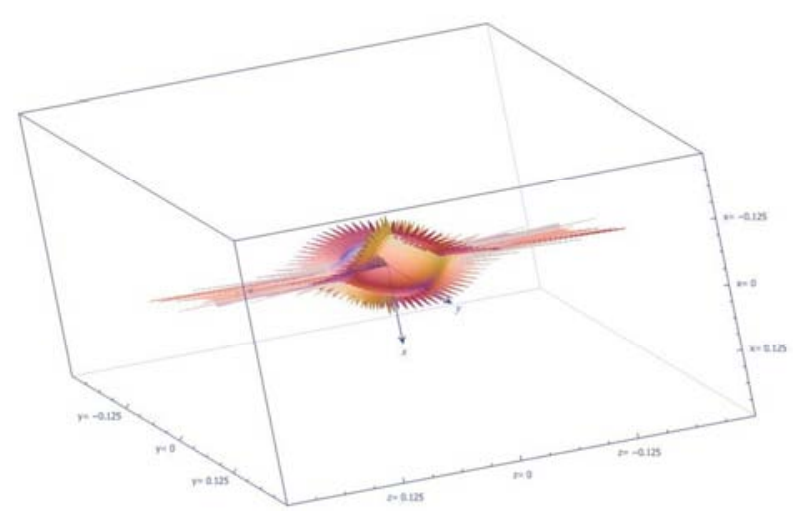

Figure 27. Neuron plasma membrane encapsulation long axis shape. 
5. Beyond meromorphic function form of $(1,3)$ order hypersphere $(1,2)$ secondary root hypersphere $(1,2)$ internal hypercube low dimension core conjugate complex hypersphere complex conjugate bud nucleus vibration effective nuclear trace function construction of neuron synapse multi-antenna spherical adsorption structure morphology. Neuronal somatic dendritic core matrix.

$$
\begin{gathered}
\operatorname{Matrix}\left[{ }^{C s c}[\operatorname{Det}(2 \times 2)]_{\text {Neuron-dendrite }}^{\text {Transcendental meromorphic }}\right]_{A 10}^{\frac{\pi}{4}, \frac{3 \pi}{4}}=-\frac{\sqrt{2}}{2}+\left[2 \operatorname{Csc}\left(y+\frac{\pi}{4}\right)+\operatorname{Sin}\left(\frac{3 \pi}{4}\right)+\operatorname{Sin}\left(\frac{3 \pi}{4}\right) \operatorname{Sin}\left(\frac{3 \pi}{4}\right)+2 \operatorname{Cos}^{2}\left(\frac{x}{2}+\frac{\pi}{4}\right)\right] \\
\operatorname{Matrix}\left[{ }^{C s c}[\operatorname{Det}(2 \times 2)]_{\text {Neuron synapse }}^{\text {franscendental meromorphic }}\right]_{A 11}^{\frac{\pi}{4}, \frac{3 \pi}{4}}=-\frac{\sqrt{2}}{2}+\left[2 \operatorname{Csc}\left(y+\frac{\pi}{4}\right)+\operatorname{Sin}\left(\frac{3 \pi}{4}\right)+\operatorname{Sin}\left(\frac{3 \pi}{4}\right) \operatorname{Sin}\left(\frac{3 \pi}{4}\right)+2 \operatorname{Cos}^{2}\left(\frac{x}{2}+\frac{\pi}{4}\right)\right]
\end{gathered}
$$

Neuronal somatic dendritic and synaptic nucleus matrix.

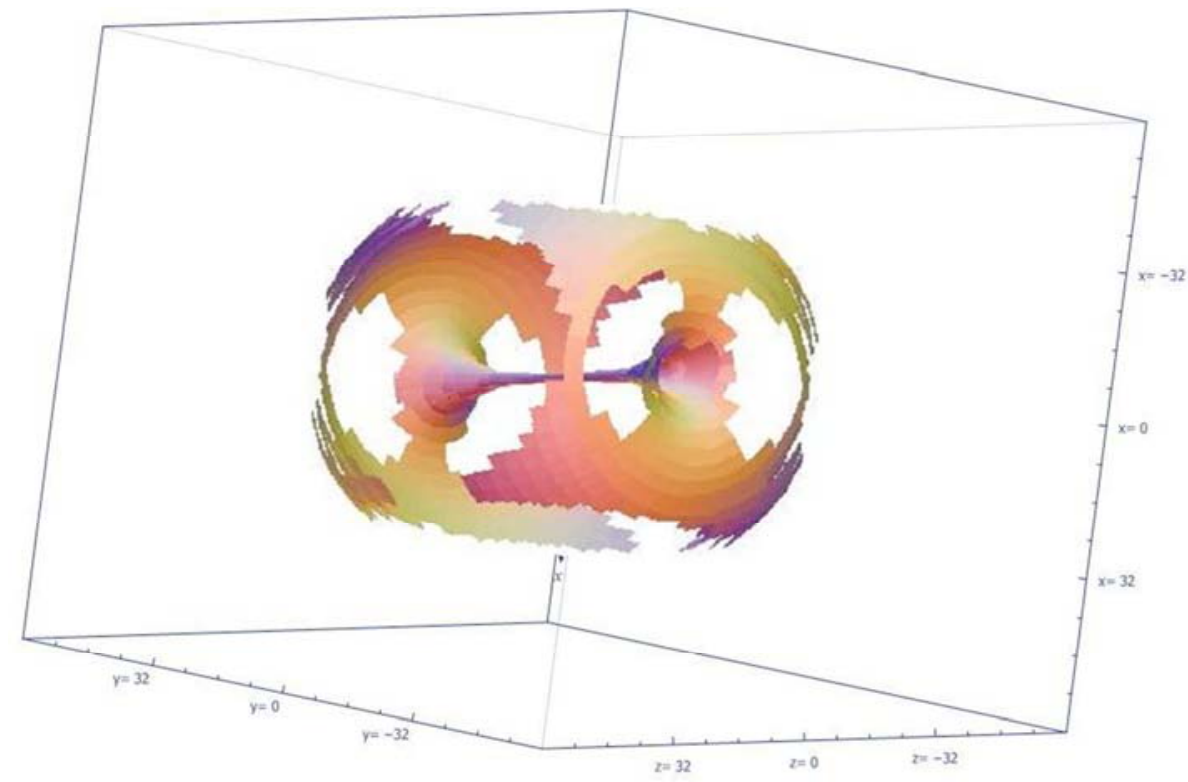

Figure 28. Vibration Kernel Mark Function of Complex Conjugate Bud Nuclei_Neuron synapse. Spherical Adsorption Structure Morphology of Complex Neurons-Synapses-Multiple Antennae.

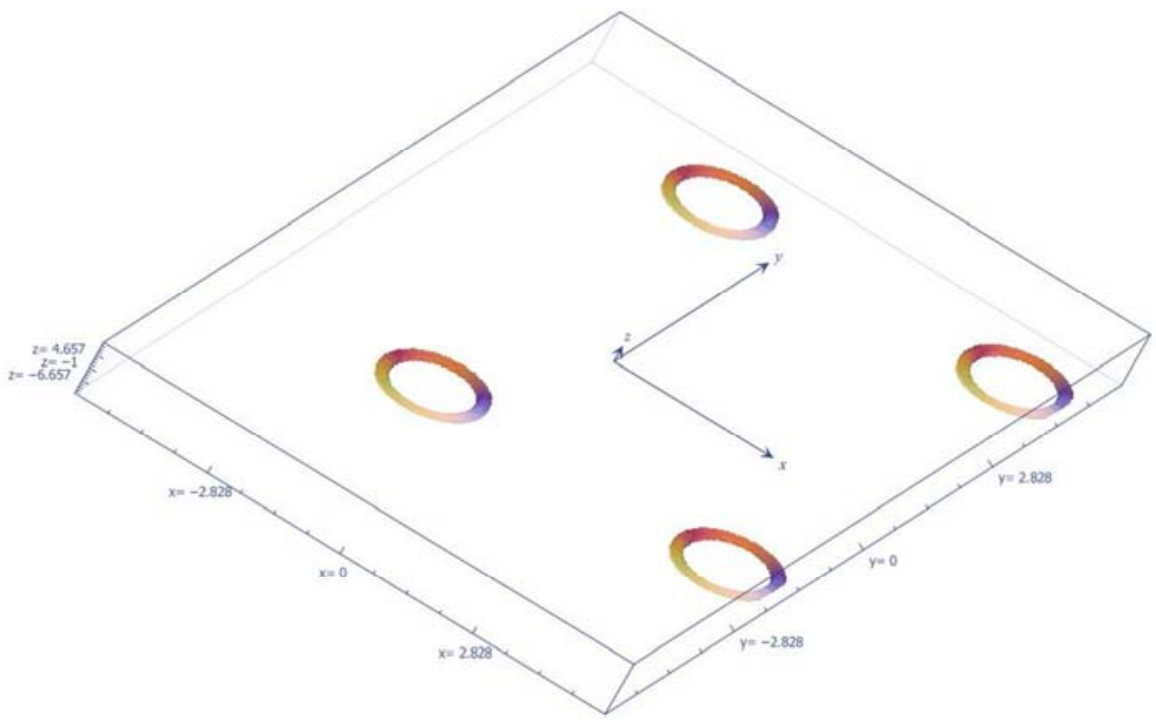

Figure 29. Neuronal cell body-nucleic acid (DNA or RNA).

Neuronal Cell Body "Rongrong zhu Nonanalytical Exploration".
Neuronal cell body-nucleic acid (DNA or RNA).

Neuronal somatic synaptic nucleus (same as neuronal 
somatic dendritic nucleus, with adjustable parameters).

Neuronal soma-synaptic nucleus matrix.

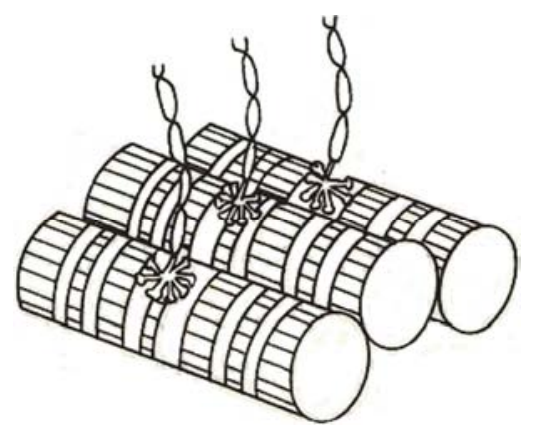

6. The results of the action of mental substance particles with radiation light. And the formula of the relationship between mental energy and images produced by human mental activities.

$$
\begin{aligned}
(\cup)\left[\int \sum_{i=1}^{n} \int\left(G_{i \text { Fear disappears }}^{\nabla}\right) d \nabla\right]= & \\
f_{\text {Image fragments }}^{-1} & {\left[\frac{1}{8} \cdot \sum \int \partial \Delta^{2}\left(\Delta M_{\text {light }}-\Delta E_{\text {Magnetic field }}\right)\right] }
\end{aligned}
$$

The formula of the relationship between mental energy and images produced by human mental activities.

Figure 30. Neuron-synapse is a mutation of neuron-tree. Spherical Adsorption Structure Morphology of Complex Neurons-Synapses-Multiple Antennae.

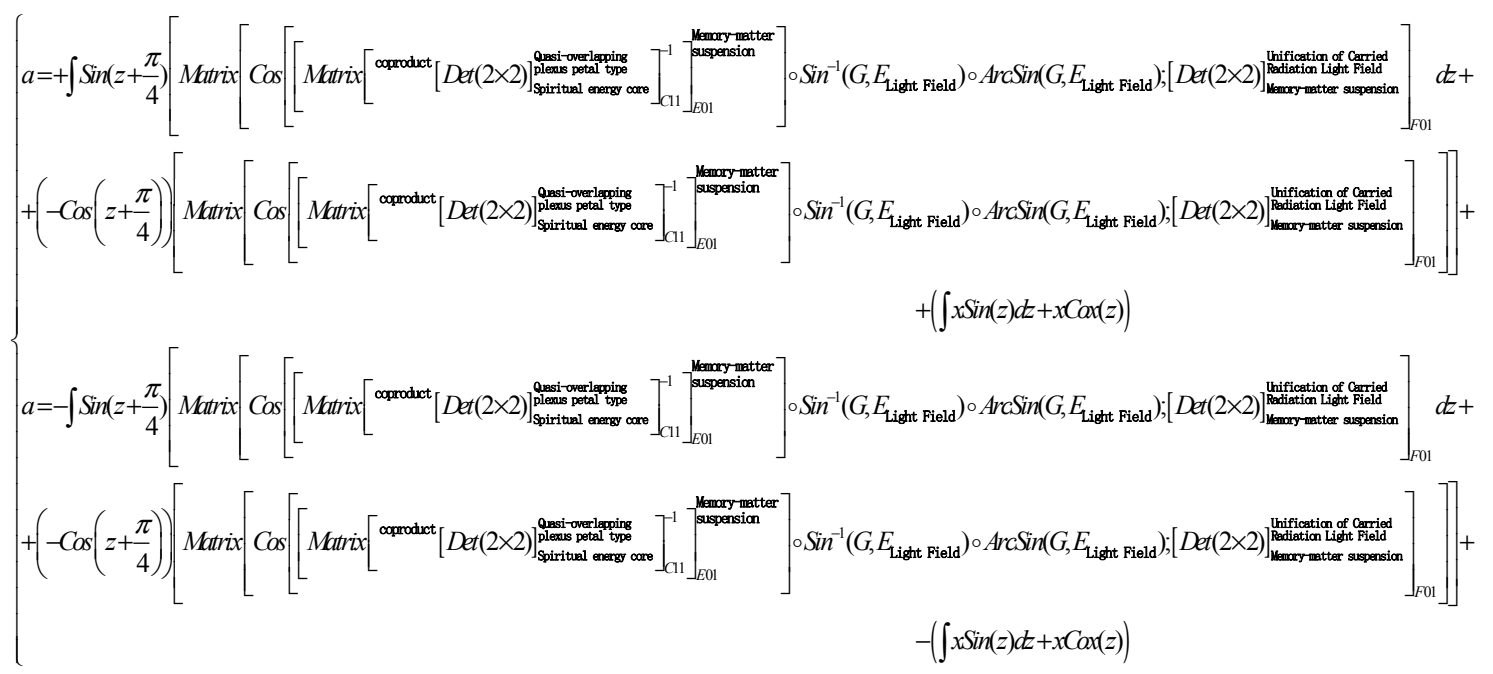

Special light field with radiation collapse of mental force causes suspension static state of substance.

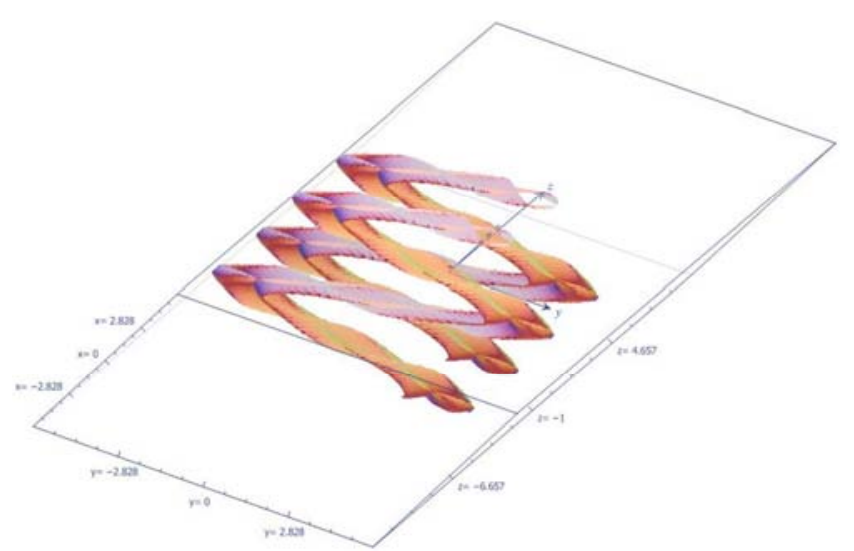

Figure 31. The collapse of the high-end hyperspherical convex spherical fiber bundles with reduced dimension in 3+1-dimension system-the special light field with radiation-mental force causes the suspension of substances in a stationary state of \$uperimposed petal-like micro-fibers."
Light field, causing mental collapse and material suspension.

Dimensional Reduction of High-end Hyperspherical Convex Fiber Clusters in 3+1 Dimensional Systems-Battle of Mind-Special Light Field with Radiation-Collapse of Spiritual Force Causes Suspended Static State of Matter_Solitary Wavelet Similarity Solutions for Global Nonlinear Partial Differential Equations in Quadratic Incremental Equilibrium Space-s1+s2 Dimensional "Stacked Cluster Petal-like Microfibers".

"Superimposed petal-like microfibers" carrying image fragments.

7. Bud Nucleus Growth Trend-Trend of Thinking and Memory, Memory Crack

The effective nucleus trace information of complex threedimensional image is formed by the effective nucleus trace information of bud nucleus vibration which is "accompanying index effectively converges the range of nucleus trace solution".

$$
\operatorname{Matrix}\left[\operatorname{function}\left(\operatorname{Sin}\left(A, \frac{\pi}{4}\right) \circ \operatorname{Sin}\left(\omega, \frac{\pi}{4}\right) ; \operatorname{Csc}(,)\right)\right]=\sqrt{\operatorname{Cos}(x+y) \operatorname{Csc}\left(x+\frac{\pi}{4}\right) \operatorname{Csc}\left(y+\frac{\pi}{4}\right) \operatorname{tg}\left(a+\frac{\pi}{4}\right)}
$$


Neuron Memory Crack (Thinking) Core kernel.

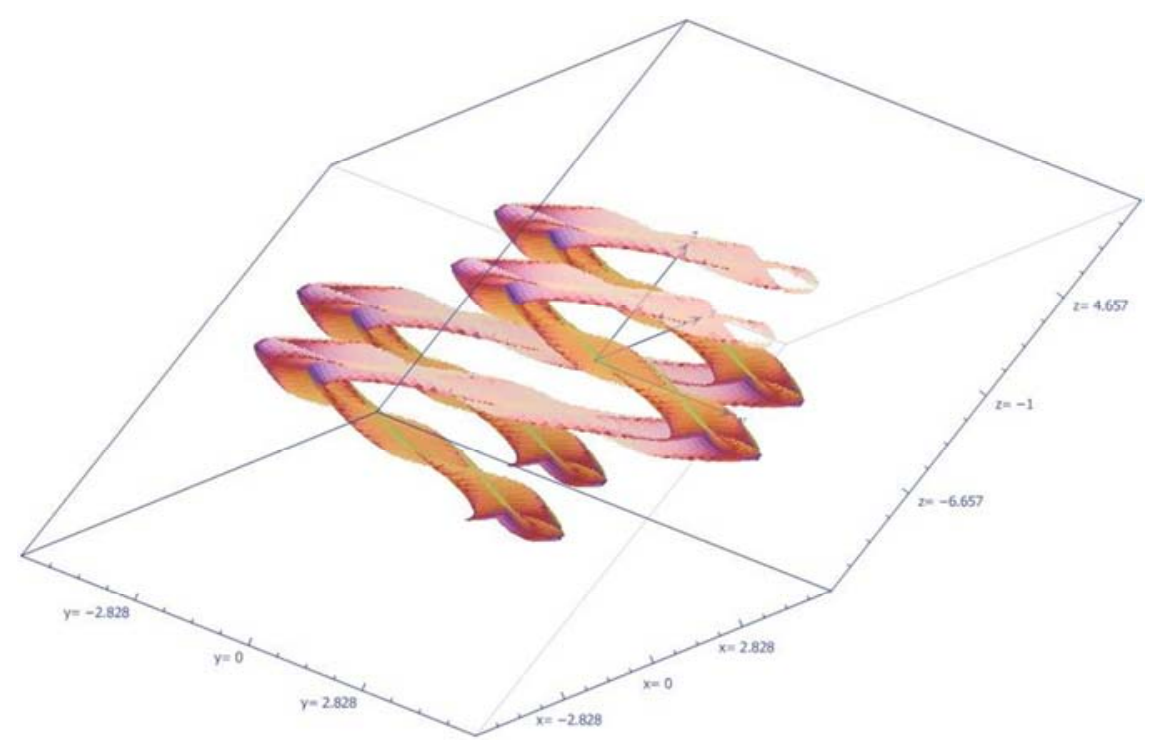

Figure 32. The collapse of the high-end hyperspherical convex spherical fiber bundles with reduced dimension in 3+1-dimension system-the special light field with radiation-mental force causes the suspension of substances in a stationary state of superimposed petal-like micro-fibers."

Prediction of nucleus formation and nucleus growth in neuron-memory fissure (thinking). Neuron Memory Crack (Thinking) Core kernel.

Ultra-three-dimensional Core Radioactive Structure in Typical Domains of Soliton-like Wave Energy Release_Similar Solution Formula of Index Equation for Complex Three-Dimensional Image Generating Bud Nucleus Growth Process

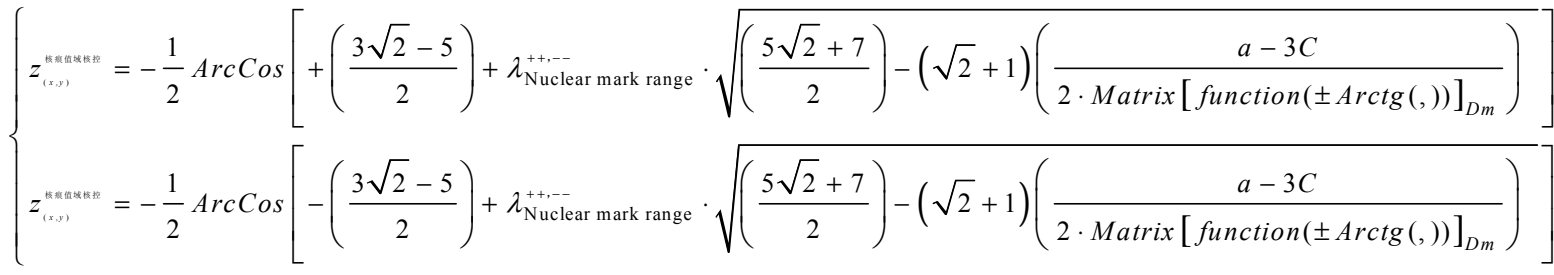

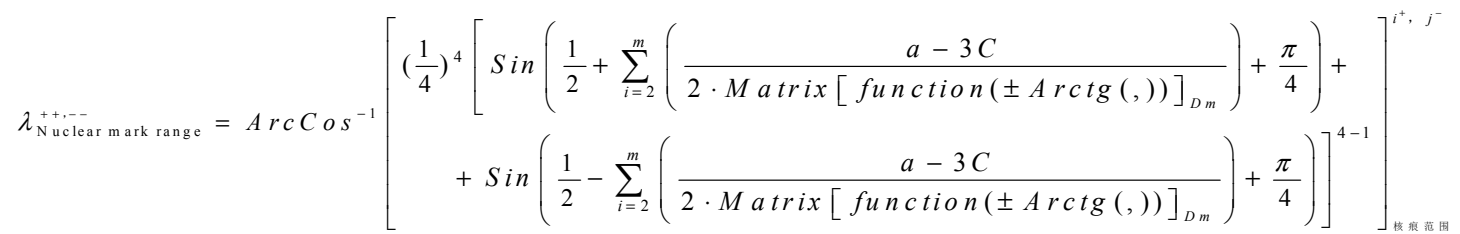

Bud Nucleus Formation Neurons Memory Rift (Thinking) Core Nucleus.

3+1-dimensional pseudo-four-dimensional system: hyperspherical convex spherical fibers cluster-spherical fibers crystallized fibers family, hyper-three-dimensional core radioactivity structure in typical domain of energy release of solitary wavelet-like, "hierarchical fuzzy clustering analysis system based on differential incremental equilibrium theory-effective nucleus trace function equation of nucleus vibration" intelligently generates complex three-dimensional images of nucleus growth process.

Human thinking activity is based on the growth trend of bud nucleus with memory material and memory fissure. Thinking activity is a special discrete energy activity process, which is closely related to memory, memory fissure and memory material.

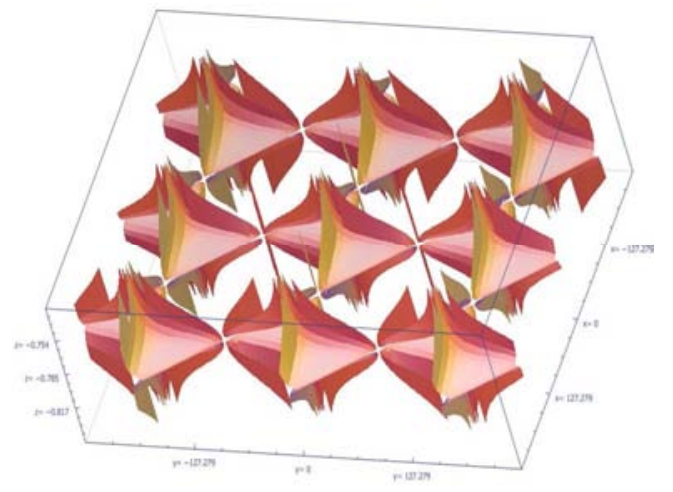

Figure 33.3+1-dimensional pseudo-four-dimensional system hyperspherical convex spherical fibers cluster-convex spherical fibers crystallized fiber family. Ultra-three-dimensional Core Radioactive Structure in Typical Domains of Soliton-like Wave Energy Release _ Similar Solutions of Index 
Equations for Complex Three-Dimensional Images Generating Bud Nucleus Growth Process.

Memory crack "bud nucleus growth trend" reflects the existence of memory fragments, some of which are interconnected and produce associative activities; and memory fragments also have some independence of memory activities.

Memory Sulcus of brain exists on a fragment of memory crack, which is a form of improving memory capacity. The existence of weak energy in memory Sulcus of brain (memory fissure) is the basis of maintaining the existence of memory information.

Bud Nucleus Growth Process of Superglobular Convex Globular Fiber Clusters.

Radioactive structure of ultra-three-dimensional core.

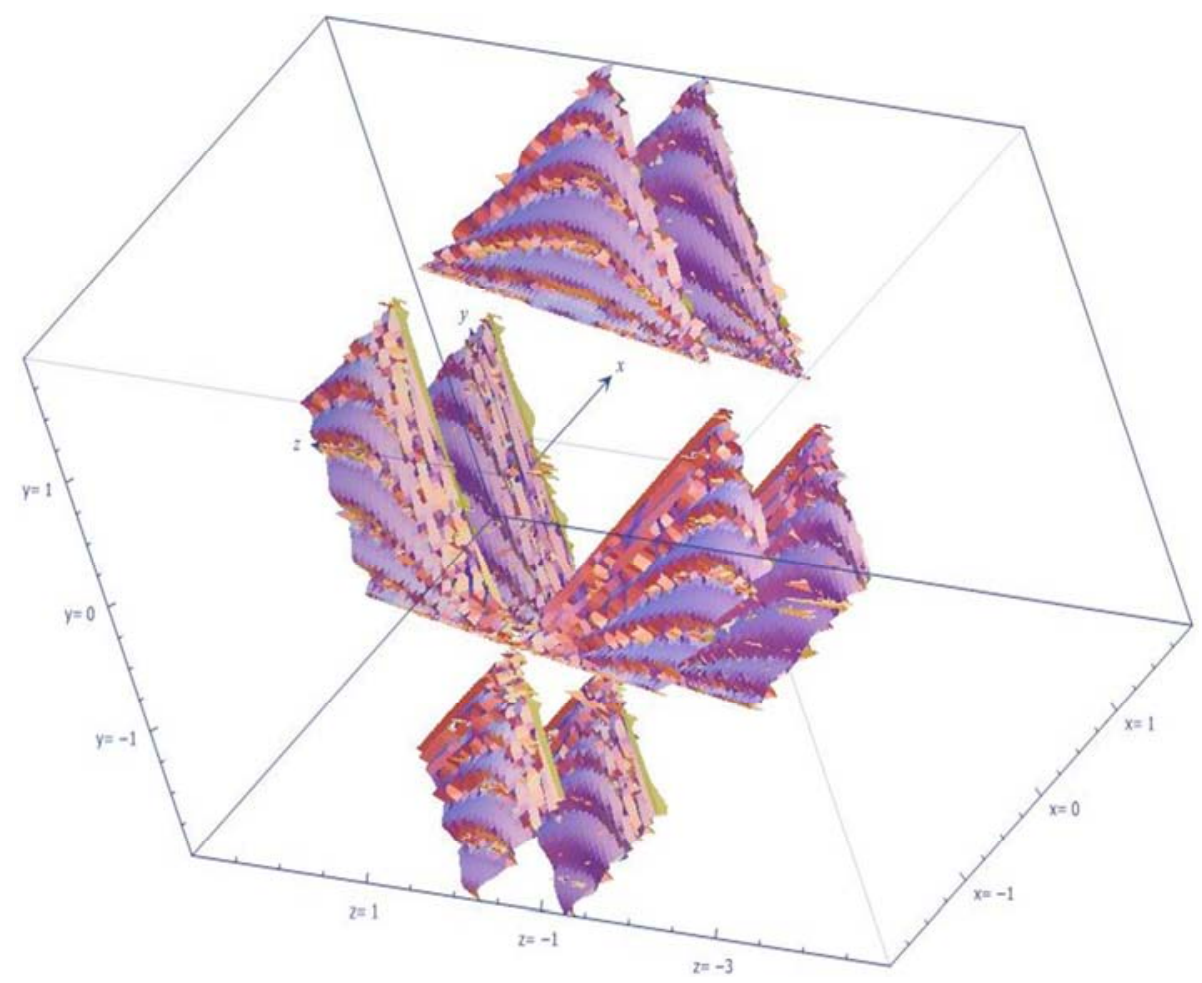

Figure 34.3+1-dimensional pseudo-four-dimensional system hyperspherical convex spherical fibers cluster-convex spherical fibers crystallized fiber family. Ultra-three-dimensional Core Radioactive Structure in Typical Domains of Soliton-like Wave Energy Release _ Similar Solutions of Index Equations for Complex Three-Dimensional Images Generating Bud Nucleus Growth Process.

8. Mind-related proteins and memory cracks as well as bud nuclei growth trends. The nucleus of neuron-memory fissure (thinking)_radioactive structure is equivalent to "neuronsynapse-neurotransmitter-flow structure".

Neuron-cell modification-cell nucleus division-binuclear 4 Polymer protein, memory fissure -radioactive structure "bud nucleus growth trend", and neuron-synapse-neurotransmitter- flow structure

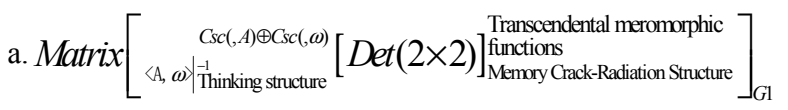

It is a cell body composed of "thinking structure variation + neuronal endonucleus intrinsic" and carries "binuclear 4 Polymer protein".

$$
\begin{gathered}
{\left[\left(\operatorname{Csc}\left(\theta+\frac{\pi}{4}\right)+\operatorname{Csc}\left(\varphi+\frac{\pi}{4}\right)\right)\left|\begin{array}{l}
\text { Thinking structure } \\
\text { Variation }
\end{array}+\operatorname{Csc}(\theta+\varphi)\right| \begin{array}{l}
\text { Chain unwinding } \\
\text { Neuron-protein }
\end{array}+\operatorname{ctg}\left(a+\frac{\pi}{4}\right) \mid \begin{array}{l}
\text { Initial boundary value } \\
\operatorname{Series} \rightarrow \sum_{i=1}^{n} \operatorname{Sin}^{i}\left(\frac{3 \pi}{4}\right)
\end{array}\right]} \\
\left.\left[\left(\operatorname{Csc}\left(\theta+\frac{\pi}{4}\right)+\operatorname{Csc}\left(\varphi+\frac{\pi}{4}\right)\right)\left|\begin{array}{l}
\text { Thinking structure Variation } \\
\text { Implication_Protein Membrane }
\end{array}+\operatorname{Csc}(\theta+\varphi)\right| \begin{array}{l}
\text { Chain unwinding } \\
\text { Neuron-protein }
\end{array}\right] \operatorname{ctg}\left(a+\frac{\pi}{4}\right) \mid \begin{array}{l}
\text { Initial boundary value } \\
\operatorname{Series} \rightarrow \sum_{i=1}^{n} \operatorname{Sin}^{i}\left(\frac{3 \pi}{4}\right)
\end{array}\right]
\end{gathered}
$$

Formulas for carrying binuclear 4-mer proteins.

Neuron-Protein-Cell Modification beyond Meromorphic Function Form Cell Core Division Memory Crack_Radioactive structure (1,3) Order Superball $(1,2)$ Secondary Root Hypersphere $(1,2)$ Inherent Supercube Cell
Body with Edge Modified Ellipsoid Form Complex Conjugated Bud Nucleus Vibration Effective Nuclear Mark Function Similarity.

$(1,2)$ Subroot $(1,3)$ Order Kernel Conjugate Complex Hyperspheres. 
Vibration nucleus trace, memory crack and radioactive structure of complex conjugated bud nucleus

b. Matrix $\left[\begin{array}{c}\operatorname{Csc}(, A) \otimes \operatorname{Csc}(, \omega) \\ \langle\mathrm{A}, \omega\rangle||_{\text {Thinking structure }}^{-1}[\operatorname{Det}(2 \times 2)]_{\text {Dinuclear_4 Polymer Protein }}^{\text {Transcendental meromorphic }}\end{array}\right]_{G 2}$

It is a large number of high-performance "neuronbinuclear-4 Polymer proteins" are needed for high-speed thinking.

"Memory cleft binuclear 4-mer protein neuron synapse" indicates that high-speed thinking requires high protein, from "mononuclear 4Polymer protein" to "binuclear 4 Polymer protein".
There is a "neurobiological" relationship between monocyte_4 polymer proteins and binuclear_4 polymer proteins, as well as a "transcendental meromorphic function morphology core conjugate complex hypersphere complex conjugate bud nucleus vibration effective nuclear trace function".

$(1,2)$ Subroot $(1,3)$ Order Kernel Conjugate Complex Hyperspheres.

Vibration Nucleus Trace, Memory Crack and Radioactive Structure of Complex Conjugated Bud Nucleus.

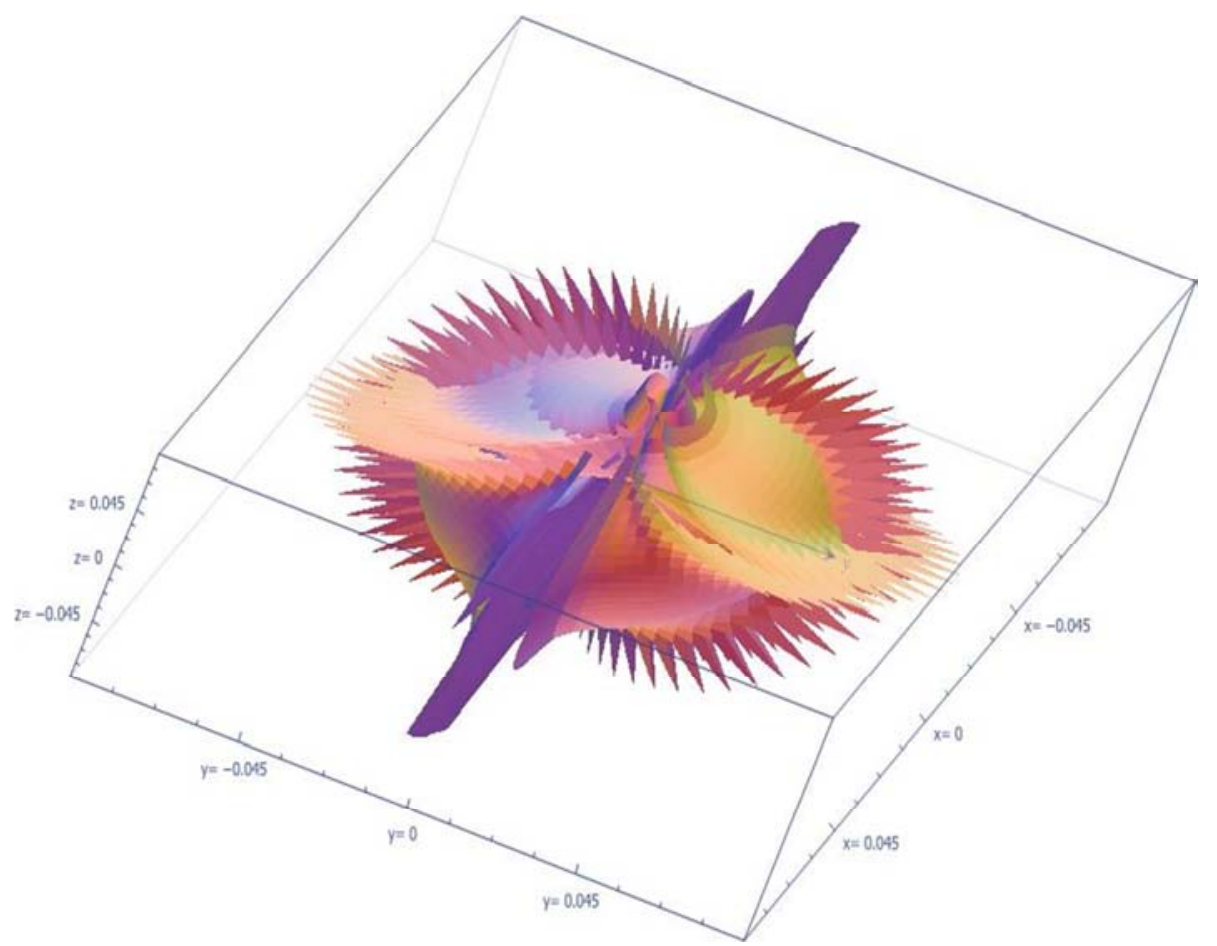

Figure 35. Neuron-Protein-Cell Modification-Cell Core Division-Memory Fissure Complex Change Conjugated Bud Nucleus Vibration Nucleus TraceMemory Fissure-Radioactive Structural Image.

\subsection{Neuronal Cells Modify the Radioactive Structure of Memory Cleft Associated with Nuclear Division}

1. Neurons (sarcoplasmic reticulum (SR) membranous cannula protein neurotransmitter glutamate (variation) chromosome degeneration cell modification cell nucleus division memory fissure radioactive structure.

The relationship between range nuclear control neuron synaptic neurotransmitter factor $\gamma^{+}$and high intelligence schizophrenia neurotransmitter glutamate (variation).

a. Neurotransmitter-glutamic acid (variation) advanced Wisdom Series $\sum_{i=1}^{n}\left(\frac{1}{x^{i}}\right)$ staining degenerative nucleus.

$$
\begin{aligned}
& \left.\operatorname{Matrix}[\langle\mathrm{A}, \omega\rangle\rangle_{\text {Thhinking structure }}^{\operatorname{Csc}(A) \otimes C S c(\omega)}[\operatorname{Det}(n \times m)]_{\text {Variation of neurotransmitter glutamate }}^{3+1 \text { Dimensional Solitary Wavelet }}\right]_{G 11,12}^{\text {Wisdom_series }}=\operatorname{Matrix}\left[\operatorname { f u n c t i o n } \left(\operatorname{Csc}\left(A, \frac{\pi}{4}\right) \otimes \operatorname{Csc}\left(\omega, \frac{\pi}{4}\right) \otimes\right.\right. \\
& \left.\operatorname{Csc}\left[\left.\sum_{i=1}^{n}\left(\frac{1}{x^{i}}\right)\right|_{x} ^{\gamma^{+} \text {factor }}, \omega\left(\operatorname{Csc}\left(y, \frac{\pi}{4}\right) \oplus \operatorname{Sin}\left(\frac{3 \pi}{4}\right) \oplus \operatorname{Cos}^{n \rightarrow 3}\left(\frac{x}{2}, \frac{\pi}{4}\right)\right) \mid \begin{array}{l}
\text { Neurotransmitter } \\
\text { glutamate }
\end{array}\right] \otimes \operatorname{ctg}\left(a, \frac{\pi}{4}\right)\right]
\end{aligned}
$$

Neurotransmitter-glutamic acid (variation) advanced wisdom-series $\sum_{i=1}^{n}\left(\frac{1}{x^{i}}\right)$-staining degenerative core formula. 


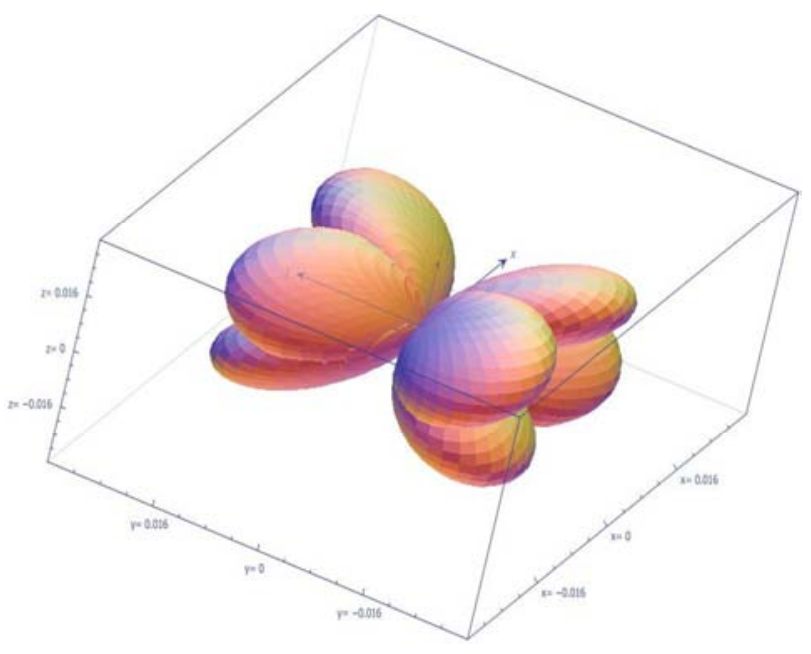

Figure 36. $(1,2)$ secondary root $(1,3)$ order core conjugated complex hypersphere, complex conjugated bud nucleus vibration nuclear mark binuclear 4 Polymer protein.

Dimensional Reduction of High-end Hyperspherical Convex Bundles in 3+1 Dimensional Systems-neurons (sarcoplasmic reticulum (SR) membranous cannula-protein) _glutamic acid (variation) _chromosome degeneration _advanced wisdom_series $\left.\sum_{i=1}^{n}\left(\frac{1}{x^{i}}\right)\right|_{x} ^{\gamma^{+} \text {factor_cell modification }}$ _cell nucleus division_memory cleavage _radioactive structure_similarity solution.

b. Core kernel structure.

The excitatory neurotransmitter has a chemical substance, glutamic acid, which is related to thinking and memory. Because of the stable control function of factor $\gamma^{+}$, advanced Wisdom Series $\left.\sum_{i=1}^{n}\left(\frac{1}{x^{i}}\right)\right|_{x} ^{\gamma^{+} \text {factor }}$, glutamate can maintain a high and stable level, but it can also keep patients in a healthy state, and the level of wisdom has been improved.

Neurons memory fissures (thinking) radioactivity solitary wavelets.

Neurotransmitter-glutamic acid (variation) -chromosomal degeneration-advanced intelligence.

From the point of view of "range nuclear control neuron synapse neurotransmitter factor $\gamma^{+}$advanced Wisdom Series $\left.\sum_{i=1}^{n}\left(\frac{1}{x^{i}}\right)\right|_{x} ^{\gamma^{+} \text {factor }}$ control mathematical model", No loss of "neuron synapse neurotransmitter", but the existence of a new and improved neurotransmitter.

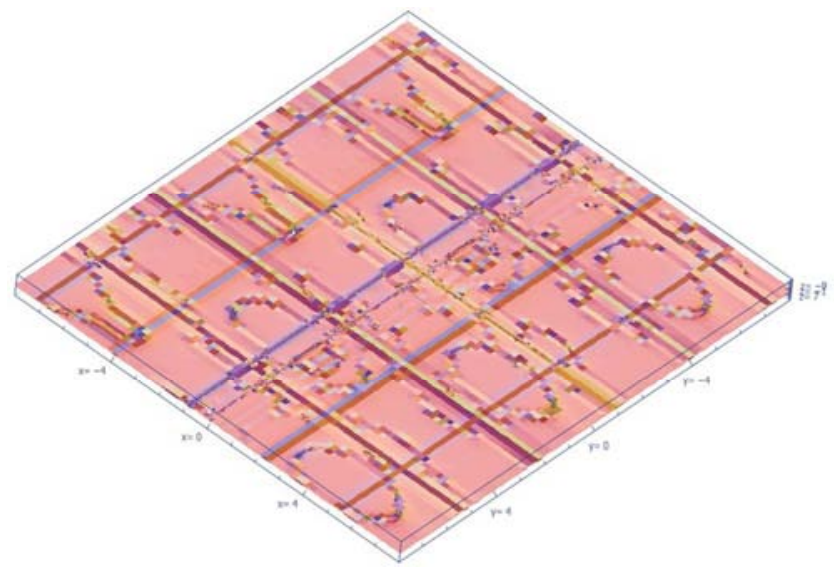

Figure 37. Memory cleft (thinking)_neurotransmitter glutamic acid (variation)_chromosome degeneration_advanced wisdom_series signal Trace mark, with hereditary images.

Complex three-dimensional image of global nonlinear partial differential equation system of 3+1-dimensional hyperspherical convex spherical fibrous plexus-neuron (sarcoplasmic reticulum (SR) membranous cannula-protein)_glutamic acid (variation) chromosome degeneration_advanced wisdom_series $\left.\sum_{i=1}^{n}\left(x^{-i}\right)\right|_{x} ^{+}$factor_cell modification cell nucleus division Memory cracks radioactive structure soliton wave value domain nuclear-controlled Arcetg analogous solution

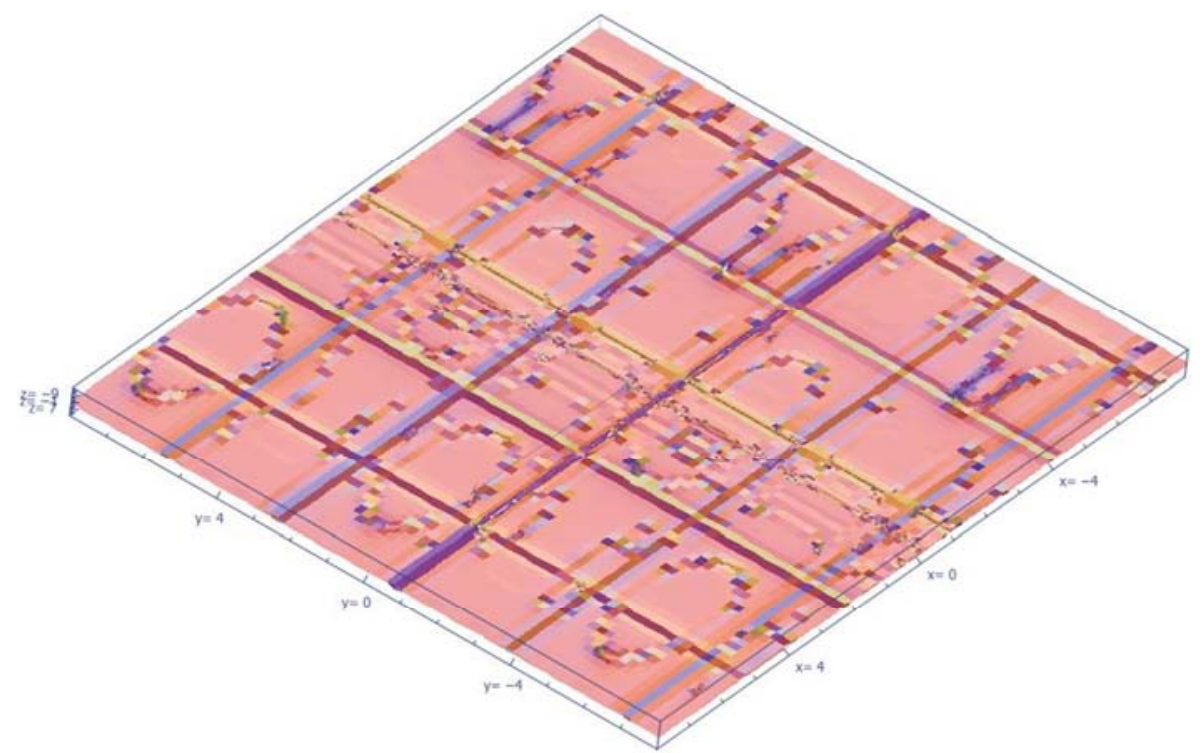

Figure 38. Memory cleft (thinking)_neurotransmitter_glutamic acid (variation)_chromosome degeneration_advanced wisdom_series signal Trace mark, with hereditary images. 


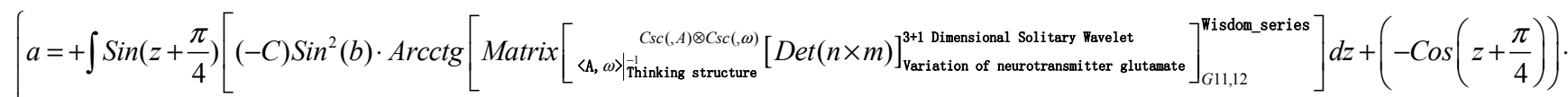

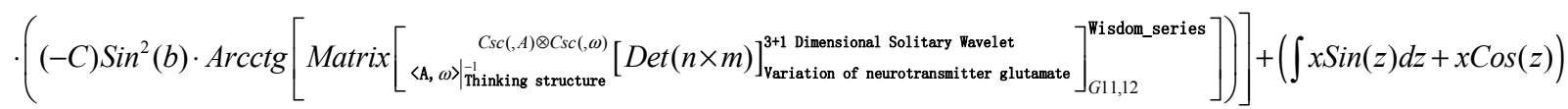

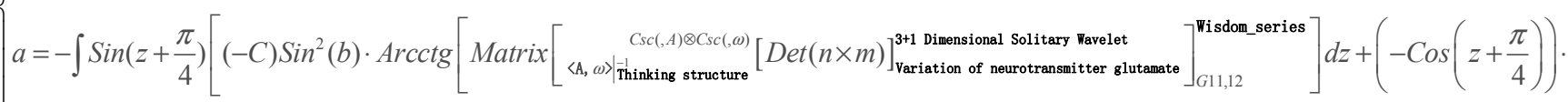

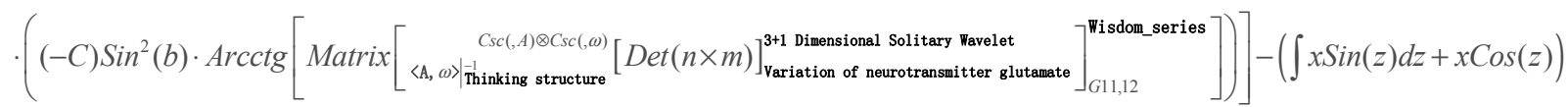

Hereditary formulas for series signal Trace mark of memory fissure (thinking)_neurotransmitter_glutamic acid (variation) _chromosome degeneration_advanced wisdom schizophrenia population.
2. High Intelligence Functional Images of Core Nuclear Factor Signal Stable Retention Situation in Schizophrenic Population.

$$
\begin{array}{r}
\text { function }\left[\gamma \text { factor, } \gamma^{-} \text {factor, } \gamma^{+} \text {factor }\right]=\left\langle\left(\sum_{i=1}^{n}\left(\frac{1}{x^{i}}\right)>0\right) ;\left(k<n \rightarrow 3 \Delta_{-}^{+}\right) \text {and } \because \operatorname{Cos} \cos ^{n}\left(\frac{x}{2}, \frac{\pi}{4}\right)\right\rangle \sim \\
\qquad\left(\frac{1}{x^{1}}+\frac{1}{x^{2}}+\frac{1}{x^{3}}+\frac{1}{x^{4}}\right) \text { or }\left(\frac{1}{x^{1}}+\frac{1}{x^{2}}+\frac{1}{x^{3}}\right) \text { or }\left(\frac{1}{x^{1}}+\frac{1}{x^{2}}+\frac{1}{x^{3}}+\frac{1}{x^{k}}\right) \text { or } \ldots \ldots
\end{array}
$$

High intelligence Schizophrenia patients have a series Signal Stable Marking formula.

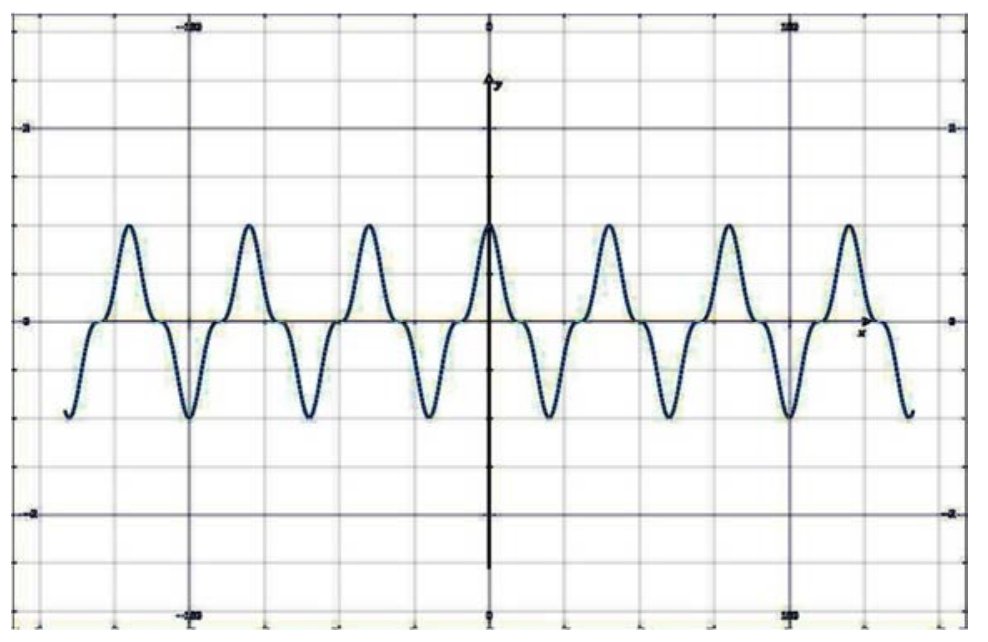

Figure 39. High memory wisdom Schizophrenia patients have series signal stable trace image.

3. "Joint Equation of Effective Nucleus Trace Function" and "Joint Equation of Effective Nucleus Trace Function for Vibration of Nucleus" reconstruct the "three-dimensional image of Effective Nucleus Trace" of the whole threedimensional image and maintain the original space position.

Highly intelligent Schizophrenic patients have regular and meaningful signal stable tracing, there is no phenomenon of edge well depth; signal stable tracing image has peaks and troughs.

How can glial cells and encapsulated brain capillaries form glioma and protein transfer --"effective nucleus mark of nucleus budding vibration" and construct nucleus mark of human brain neurovascular lesions.

$$
\begin{array}{r}
\operatorname{Matrix}\left[\begin{array}{c}
\operatorname{Csc}_{(,)} \oplus \operatorname{Cos}^{n-1}(,) \\
J_{-} \text {Plasma membrane }+\operatorname{protein}
\end{array}[\operatorname{Det}(n \times m)]_{\text {Glial cells }}^{\text {Transcendental meromorphic functions }}\right]_{J 1}^{\text {Direct sum }}=\left[-\sqrt{2} / 2 \oplus \operatorname{Csc}(\varphi,) \oplus \operatorname{Sin}(3 \pi / 4) \oplus \operatorname{Cos}^{n-2}(\theta / 2,)\right. \\
\oplus\left[\left(\operatorname{Sec}\left(\operatorname{Cos}\left(\theta /\left.2\right|^{\text {Synthetic protein_RNAorDNA }},\right)+\operatorname{Csc}\left(\left.\varphi\right|^{\text {Protein Shell (Coat) }},\right)\right)\right) \oplus \operatorname{ctg}(a,) ; \pi / 4\right]
\end{array}
$$

Matrix Kernel-Formula of Glial Cells.

Complex conjugated nucleus vibrating nuclear mark-glial cells. Neurons degeneration glial cells long handle ellipsoid. 


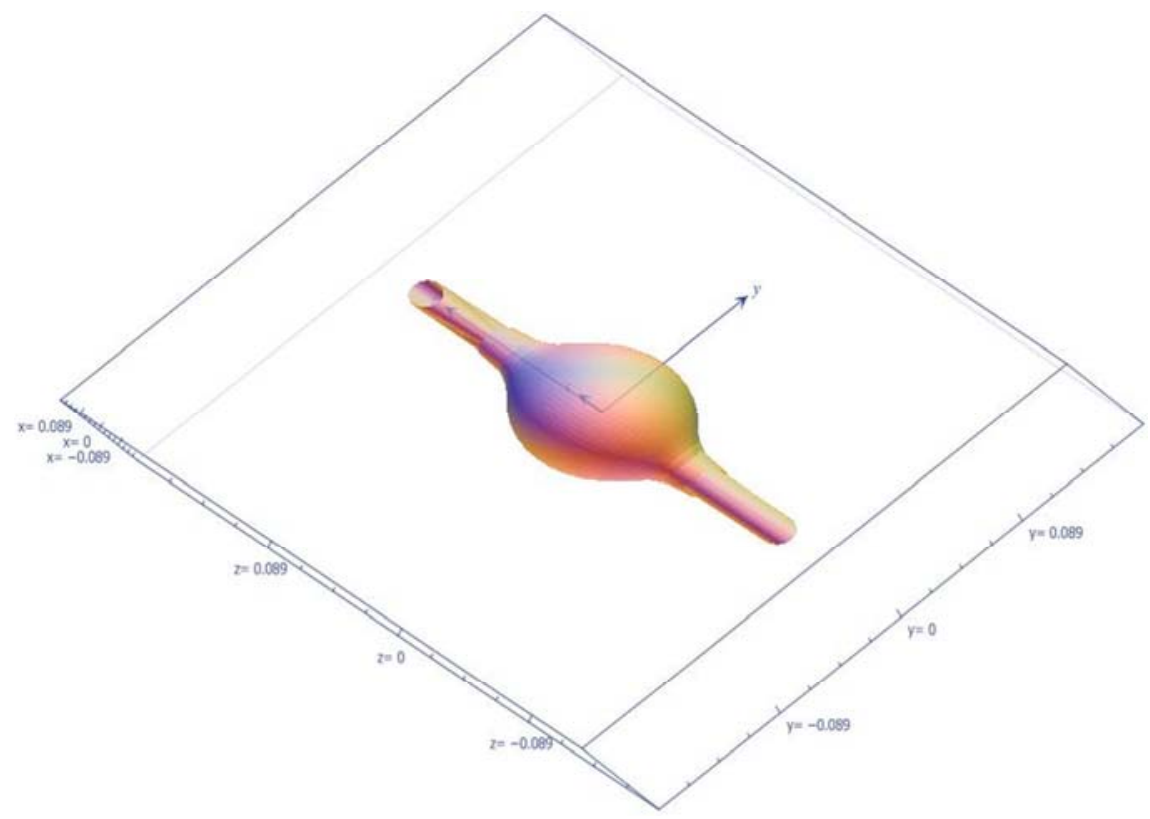

Figure 40. Neurons degeneration glial cells long handle ellipsoid image.

Neuroependymal cells-matrix nucleus of glioma.

$$
\begin{aligned}
& \operatorname{Matrix}\left[{ }_{J_{-} \text {Plasma membrane }+ \text { protein }}^{C \operatorname{Csc}\left(\operatorname{Cot}^{n-1}(,)\right.}[(n \times m)]_{\mathrm{Glioma}}^{\text {Transcendental meromorphic functions }}\right]_{J 2}^{\text {Direct sum }}=\left[-\sqrt{2} / 2 \oplus \operatorname{Csc}^{\prime \prime}(\varphi,) \oplus \operatorname{Sin}(3 \pi / 4) \oplus\left(\operatorname{Cos}^{n-2}(\theta / 2,)\right)\right)^{\prime \prime} \\
& \oplus\left[\left(\operatorname{Sec}\left(\operatorname{Cos}^{\prime \prime}\left(\theta /\left.2\right|^{\text {Synthetic protein_RNAorDNA }},\right)+\operatorname{CSc}^{\prime \prime}\left(\left.\varphi\right|^{\text {Protein Shell (Coat) }},\right)\right)\right) \oplus \operatorname{ctg}(a,) ; \pi / 4\right]
\end{aligned}
$$

Matrix Kernel-Formula for Neuroependymal Cells and Gliomas.

Complex conjugated nucleus vibrating nuclear mark-glial cells. Neurons degeneration glial cells long handle ellipsoid.

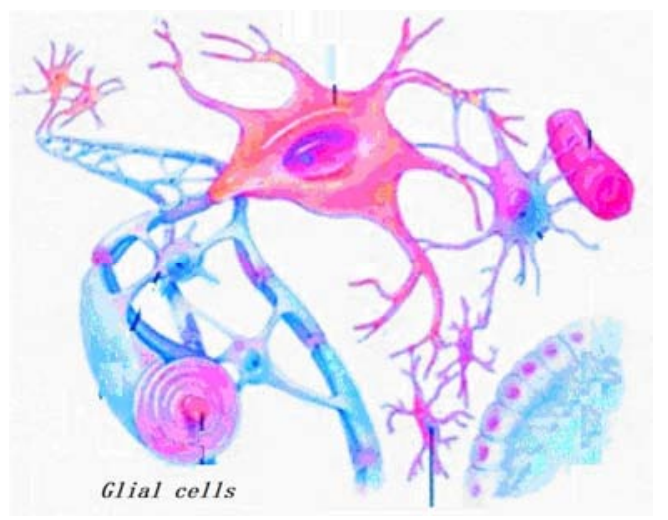

Figure 41. Neurons degeneration glial cells long handle ellipsoid image.

Complex conjugated nucleus vibrating nuclear mark-glial cells. Neuronal degeneration glial cells compressive ellipsoid.

Glial cells and protein transfer cell modification cell nucleus division _ transcendental meromorphic function $(1,3)$ order hypersphere $(1,2)$ secondary root hypersphere _internal hypercube low dimension long handle ellipsoid shape internal conjugate complex hypersphere conjugate bud nucleus vibration effective nuclear trace function similarity solution spherical polar coordinate system.

Glial cells and proteins metastasize and form glioma cells, cell modification, cell nucleus division, transcendental meromorphic function $(1,3)$ order hypersphere $(1,2)$ secondary root hypersphere internal hypercube low dimensional long handle ellipsoid shape internal nucleus conjugate complex hypersphere conjugate bud nucleus vibration effective nuclear mark function similarity solution spherical polar coordinate system.

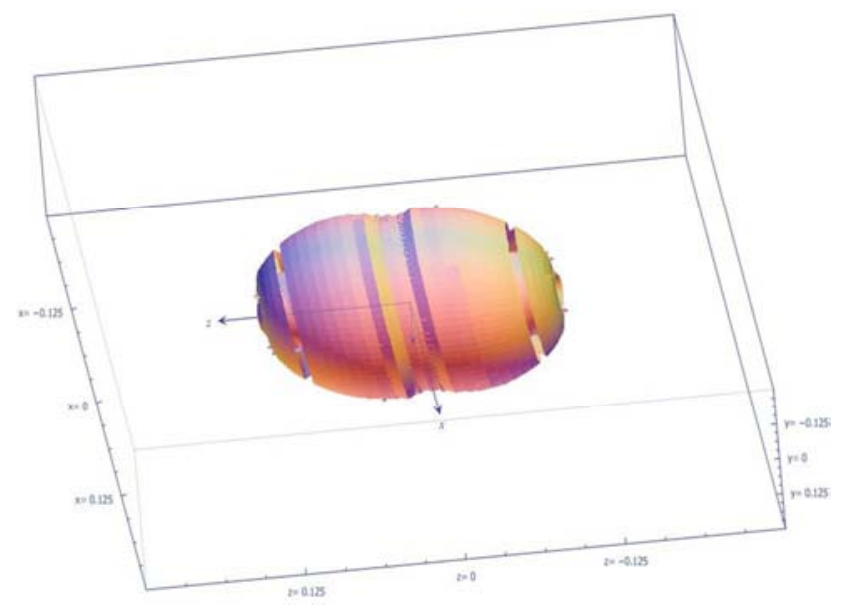

Figure 42. Neurons degeneration glial cells double ellipsoid - image. 


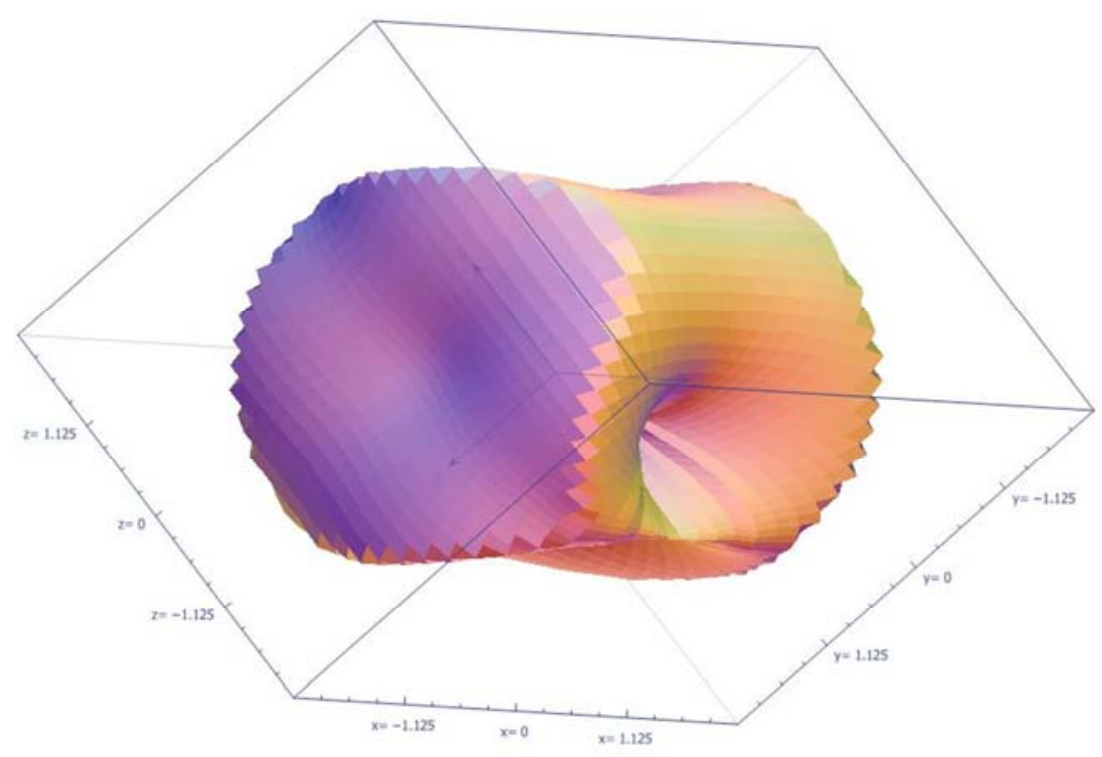

Figure 43. Neurons degeneration glial cells compressive ellipsoid - image.

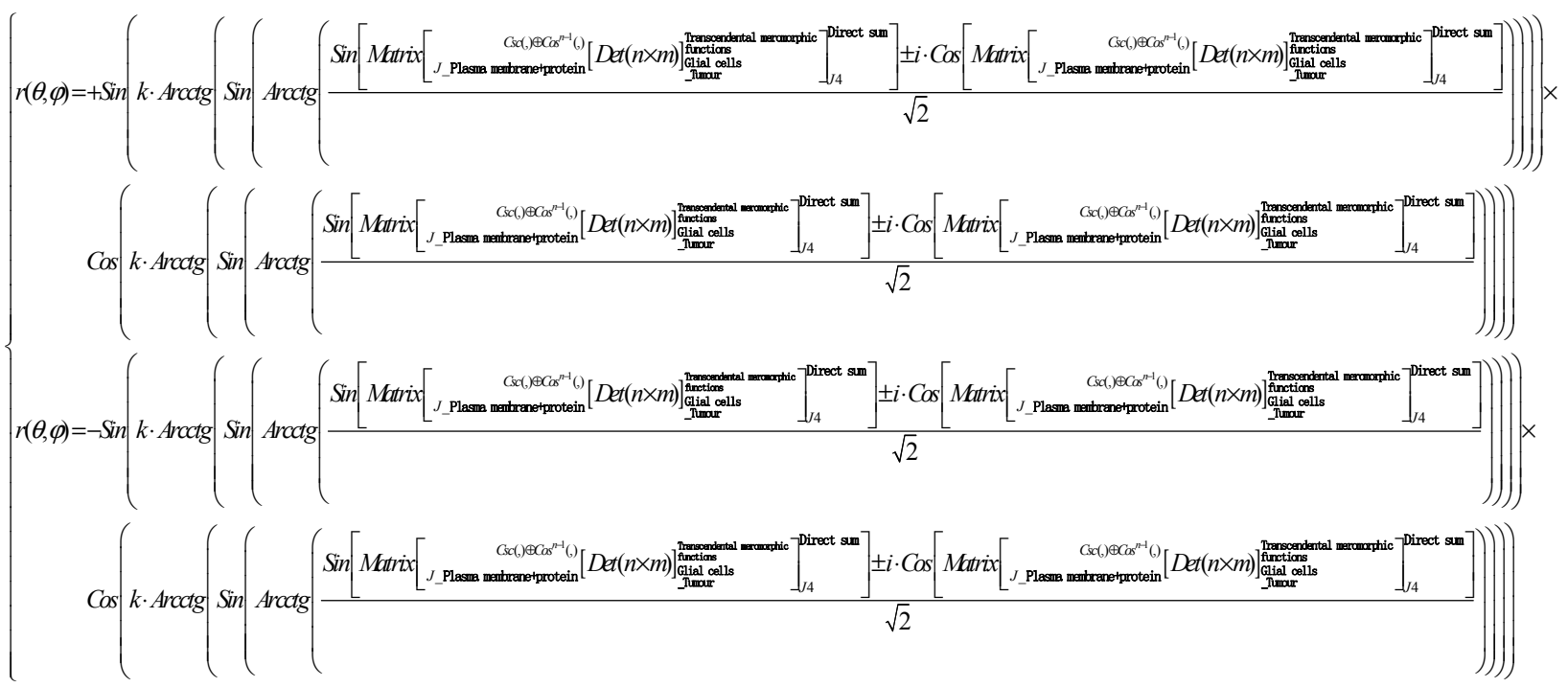

Neurons degeneration glial cells double ellipsoid - formula.

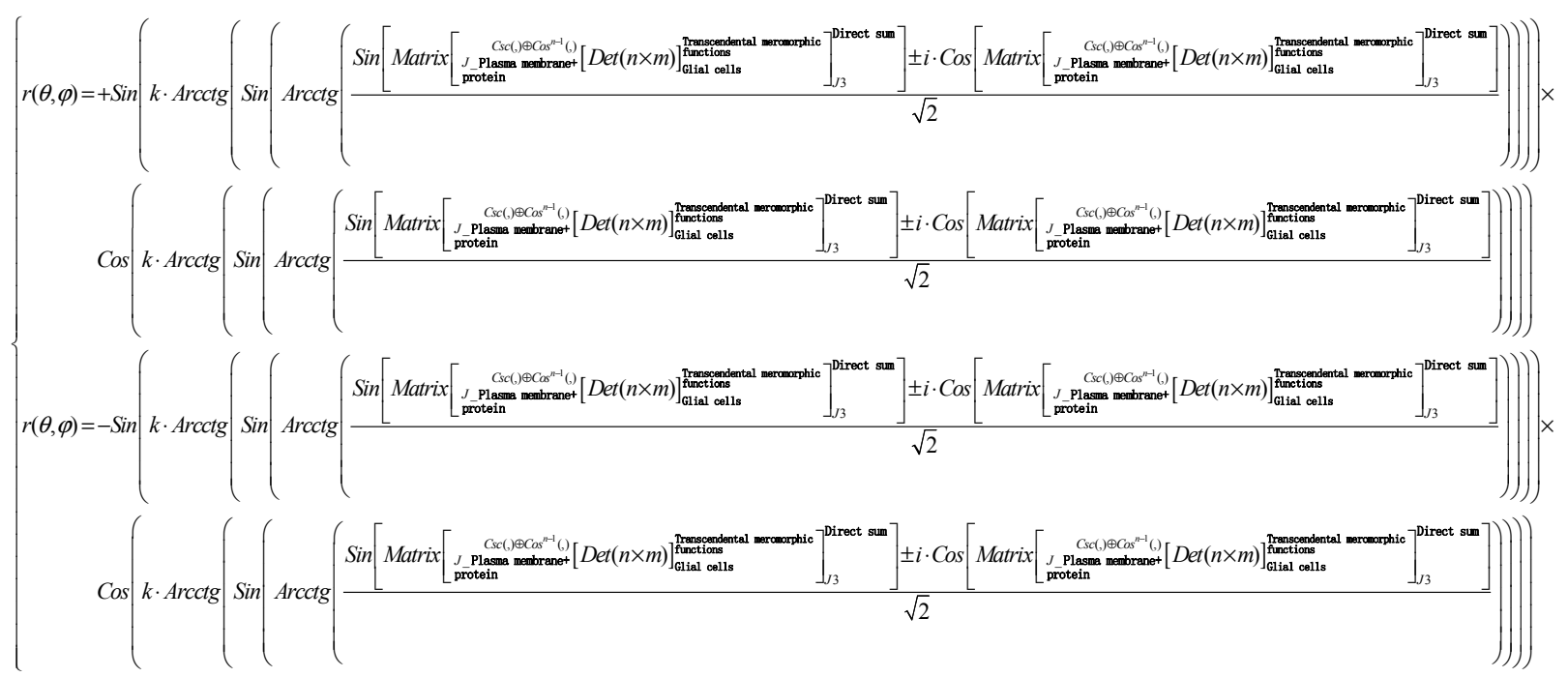


Neurons degeneration glial cells compressive ellipsoid formula.

\subsection{The Structure of Capillary Membrane and the Change of Neuron Cell Body}

1. "Capillary-Membrane Structure-Cell" Cells: Plasmid+Protein, Capillary-Ependymal Structure-CellModified Membrane Protein Structure.
Capillary ependymal structure cells, forming variant nuclear structure cell modification cell nucleus division, transcendental meromorphic function $(1,3)$ order hypersphere $(1,2)$ secondary root hypersphere_inner hypercube low dimension_Effective Kernel Mark Function for Vibration of Tube-like MorphologyCore Conjugated Complex Hypersphere-Complex Conjugated Bud Nucleus-General Solution of Similar Solution-Spherical Polar Coordinate System.

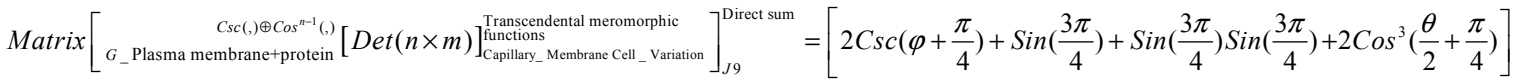

$$
\begin{aligned}
& \oplus\left[\left(-\frac{\sqrt{2}}{2}+2 \operatorname{Csc}\left(\varphi+\frac{\pi}{4}\right)+\operatorname{Sin}\left(\frac{3 \pi}{4}\right)+\operatorname{Sin}\left(\frac{3 \pi}{4}\right) \operatorname{Sin}\left(\frac{3 \pi}{4}\right)++2 \operatorname{Cos}^{2}\left(\frac{\theta}{2}+\frac{\pi}{4}\right)\right)+\operatorname{ctg}\left(a+\frac{\pi}{4}\right)\right]
\end{aligned}
$$

Capillary ependymal structure (cell) mutant core.

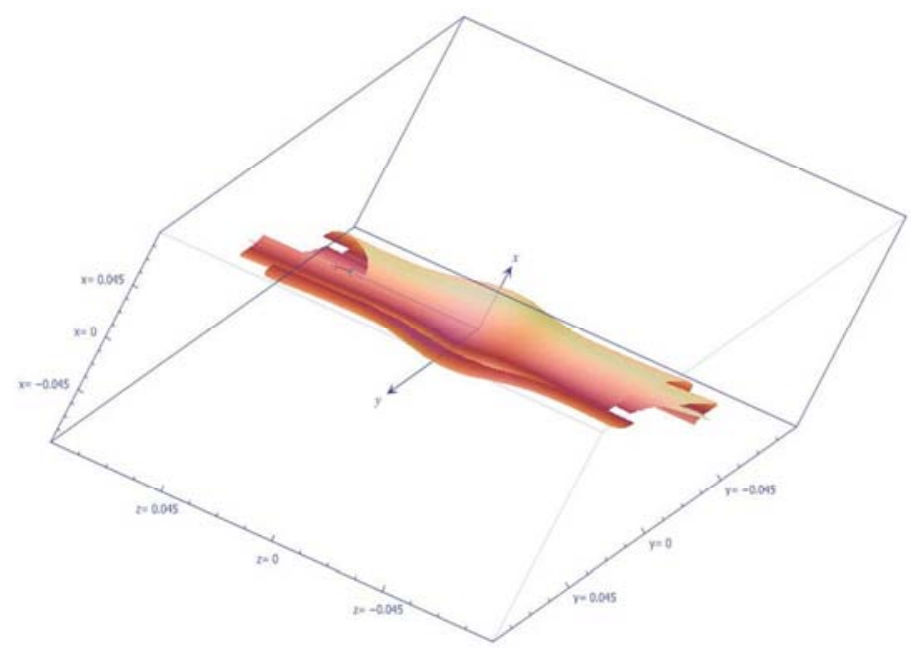

Figure 44. Complex conjugated bud nuclei vibrate nucleus marks capillaries, and capillaries membranous structures (cells) variant nuclei.

2. "Neuron Change Cell Body" Cells: Plasma Membrane + Protein, Neuron change cell body cell modification membrane protein structure.

Neurons are complex cellular structures with both somatic nuclei and neuronal soma (thinking-type nuclear structure) and the same DNA or RNA.

Neurons changes cell bodies cells, where the possibility of tumorigenesis is extremely low, but accompanied by glioma, chromosome (DNA or RNA), protein does not necessarily mutate.

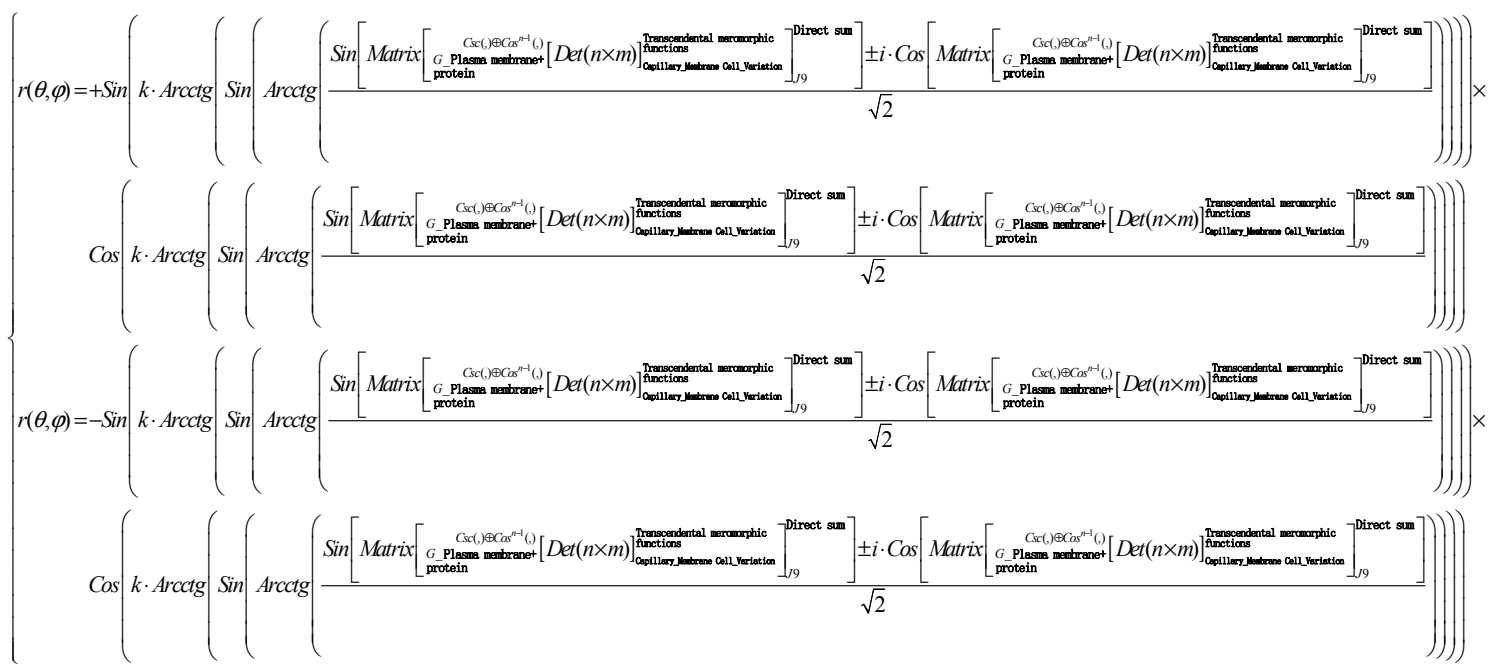


Capillary ependymal structure cells form mutant endonuclear structure cell modification cell core division, transcendental meromorphic function $(1,3)$ order hypersphere $(1,2)$ secondary root hypersphere _ inner root hypersphere low dimension tubular membrane shape inner nuclear conjugated hypersphere conjugated bud nucleus vibration effective nuclear trace function similarity solution-formula.

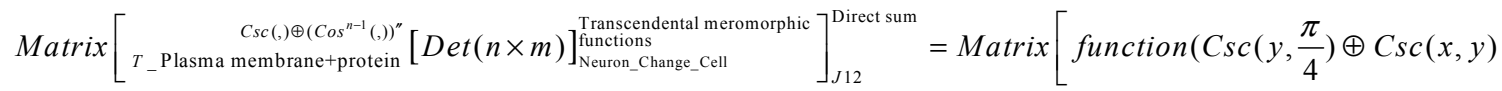

$$
\begin{aligned}
& \left.\left.\oplus \sum_{i=1}^{n-1} \operatorname{Sin}^{i} \frac{3 \pi}{4} \oplus \frac{d^{2}}{d x^{2}} \operatorname{Cos}^{n-1}\left(, \frac{\pi}{4}\right)\right)\right]
\end{aligned}
$$

Core-core structure of neuron-change-cell body-cell modification-membrane protein structure.

Neuron change cell body cell nucleus (second-order differential DNA abnormality) can hardly form tumor structure cell modification.

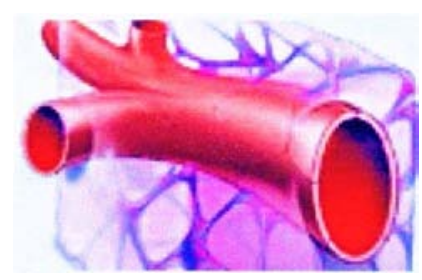

Figure 45. Complex conjugated bud nuclei vibrate nucleus marks capillaries, and capillaries membranous structures (cells) variant nuclei.

The reason is that in the transcendental meromorphic function system of neuron-change-cell body-cell first-order differential protein-shell+second-order differential chromosome (DNA or RNA), the structure of tumor type can hardly be formed. Whether "neuron-cell body (cell)" tumors exist in "molecular cytobiology".

Cell division, transcendental meromorphic function $(1,3)$ order hypersphere $(1,2)$ secondary root hypersphere_inner hypercube low dimension ellipsoid state inner nucleus conjugated hypersphere conjugated bud nucleus vibration effective nuclear trace function similarity solution spherical polar coordinate.

Neuron change cell body cell first-order differential protein capsid mutation + nucleus (second-order differential DNA abnormality) can hardly form tumor structure cell modification cell core division,

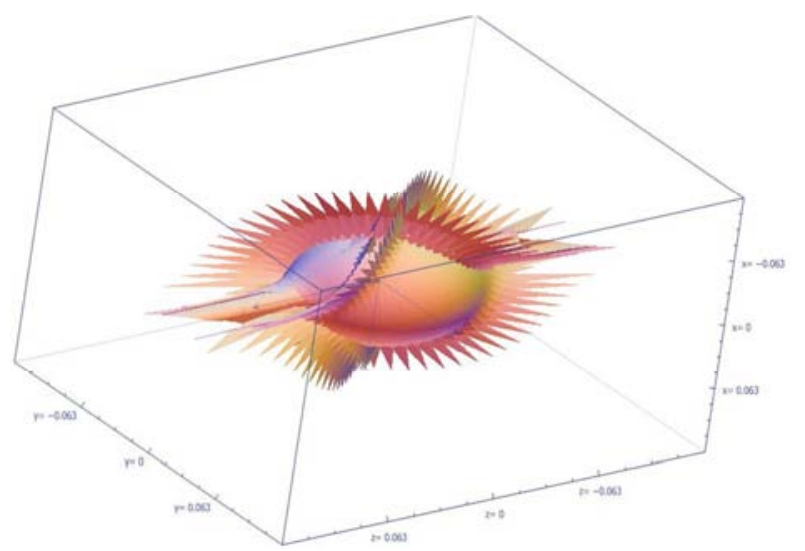

Figure 46. Subradical-order kernel conjugate complex hyperspheres, and the vibratory nuclear mark of the complex conjugate bud nucleus neuron change cell body.

\section{Discussion}

1. The effects of differential incremental equilibrium geometry- Sulcus of brain and protein particle movement on thinking space and mental activity, and the 4-dimensional super-high-end superspherical convex spherical fibrous plexus "redundant, stacked petal-like microfibers".

Brain science, which embodies the successful intervention of original geometry in molecular cell biology, can express neurons, neuron cell bodies, transcendental meromorphic function $(1,3)$ order hypersphere $(1,2)$ secondary root hypersphere_internalhypersphere low-dimensional ellipsoid state endonuclear conjugate hypersphere conjugate bud nucleus vibration effective nuclear trace function analogy solution Label system.

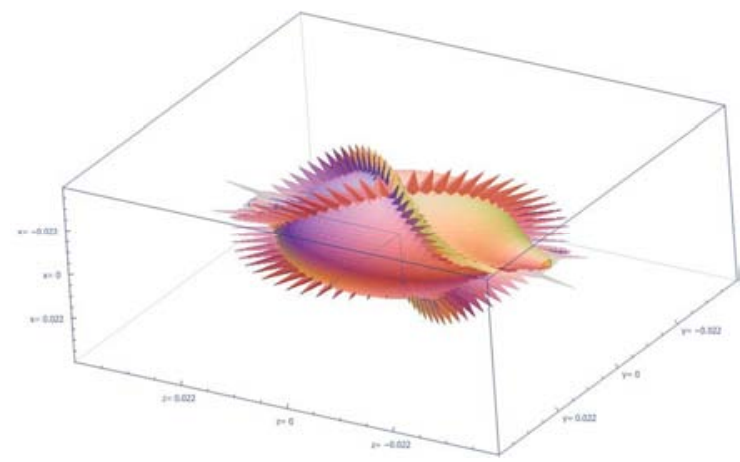

Figure 47. Subradical-order kernel conjugate complex hyperspheres, and the vibratory nuclear mark of the complex conjugate bud nucleus neuron change cell body.

Neuron (protein structure)_4 Polymer proteins, neuronbinuclear-4 Polymer proteins, memory fissures (thinking)_neurotransmitters, neuron-degeneration_glial cells from genome to protein space folding, Forming the topological geometry of various nerve cells.

It forms a brain-like system with intrinsic life forms, and the movement of high-energy protein particles profoundly influences thinking and mental activities, so as to form a hybrid artificial intelligence of life and machine.

Transmeromorphic function Complex conjugate nucleus vibration effective nucleus mark, In the complex function theory, the absolute supersymmetry geometry of Binuclear 4mer proteins is discussed.

2. Brain-like science is studied from another brand-new angle. The mature deduction of brain mathematics provides a deeper fitting structure for brain-like science.

This is a special problem, which is the unification of 
variation and heterogeneity, and also the centralized embodiment of heterosexual interchangeability. He provides a scientific basis for revealing the strong fitting function of brain science.

It provides information science and life science support for future 3D printing technology of tissues and organs.

\section{Conclusion}

Differential incremental equilibrium geometry has its supersymmetric topological geometry. Build Differential Incremental Equilibrium Geometry-Effects of Cerebral Groove and Protein Granule Motion on Thinking Space and Mental Activity, 4-dimensional Super-High-end Super-Spherical Convex Spherical Fiber Cluster, Coproduct -Like Cluster Petal Microfibers. There are also brain like mental activity traits in the spatial construction of research in the field of psychiatry with the fluid morphology of neurotransmitters. From the perspective of molecular cell biology, the spatial structure of brain like structure, brain, nervous system and neurotransmitter were constructed. It really establishes the internal structure and law of molecular cell biological model, and embodies the new field of brain like research.

\section{References}

[1] C. Rogers W. K. Schief, Bäcklund and Darboux Transformations: Geometry and Modern Applications in Solition Theory, first published by Cambridge University, 2015: 1-292.

[2] Chen Zhonghu, Lie group guidance, Higher Education Press, 1997: 1-334.

[3] Ding Peizhu, Wang Yi, Group and its Express, Higher Education Press, 1999: 1-468.

[4] E. M. Chirka, Complex Analytic Sets Mathematics and Its Applications, Kluwer Academic Publishers Gerald Karp, Cell and Molecular Biology: Concepts and Experiments (3e), Higher Education Press, 2005: 1-792.

[5] Gong Sheng, Harmonic Analysis on Typical Groups Monographs on pure mathematics and Applied Mathematics Number twelfth, Beijing China, Science Press, 1983: 1-314.

[6] $\mathrm{Gu}$ Chaohao, $\mathrm{Hu}$ Hesheng, Zhou Zixiang, Dar Boux Transformation in Solition Theory and Its Geometric Applications (The second edition), Shanghai science and technology Press, 1999, 2005: 1-271.

[7] Jari Kaipio Erkki Somersalo, Statistical and Computational Inverse Problems With 102 Figures, Spinger.

[8] Lou Senyue, Tang Xiaoyan, Nonlinear Mathematical Physics Method, Beijing China, Science Press, 2006: 1-365.

[9] Numerical Treatment of Multi-Scale Problems Porceedings of the $13^{\text {th }}$ GAMM-Seminar, Kiel, January 24-26, 1997.

[10] Notes on Numerical Fluid Mechanics Volume 70 Edited By Wolf Gang Hack Busch and Gabriel Wittum.

[11] Qiu Chengtong, Sun Licha, Differential Geometry
Monographs on pure mathematics and Applied Mathematics Number eighteenth, Beijing China, Science Press, 1988: 1403.

[12] Ren Fuyao, Complex Analytic Dynamic System Shanghai China, Fudan University Press, 1996: 1-364.

[13] Shou Tiande, Neurobiology (2e) Higher Education Press, 2001, 2006: 1-548.

[14] Shou Tiande, Neurobiology, Higher Education Press, 2001, 2003: 1-470.

[15] Su Jingcun, Topology of Manifold, Wuhan China, Wuhan university press, 2005: 1-708.

[16] TECHNIQUES D' Analyse MATHE'MATIQUE 1968 Masson etC ${ }^{\text {ie }}$, Paris. Imprimé en France Wave Packet Analysishristoph Thiele Numer 105 Library of Congress Cataloging-inPublication.

[17] Data Thiele. Christoph, 1968 Wave packet analysis / Christoph Thielep. (Regional conference series in mathematics. ISSN 0160-7642: no. 105).

[18] W. Miller, Symmetry Group and Its Application, Beijing China, Science Press, 1981: 1-486.

[19] Wu Chuanxi, Li Guanghan, Submanifold geometry, Beijing China, Science Press, 2002: 1-217.

[20] Xiao Gang, Fibrosis of Algebraic Surfaces, Shanghai China, Shanghai science and technology Press, 1992: 1-180.

[21] Zhang Wenxiu, Qiu Guofang, Uncertain Decision Making Based on Rough Sets, Beijing China, tsinghua university press, 2005: 1-255.

[22] Zheng jianhua, Meromorphic Functional Dynamics System, Beijing China, tsinghua university press, 2006: 1-413.

[23] Zheng Weiwei, Complex Variable Function and Integral Transform, Northwest Industrial University Press, 2011: 1396.

[24] LABPHTEB M. A., Tria BAT B. B., Methods of Function of a Complex Variable Originally published in Russian under the title, 1956, 2006: 1-287.

[25] Tang Hua, Principle and application of RNA interference, Beijing China, Science Press, 2006: 1-482.

[26] Wang Jiankang, Applied quantitative genetics, China Agricultural Science and Technology Press, 2007: 1-269.

[27] J. Barciszewski, V. A. Erdmann, Noncoding RNAs: Molecular Biology and Molecular Medicine, Chemical Industry Press, 2008: 1-299.

[28] Jin Youxin, Zhao Botao, Ma Zhongliang, TECHNIQUES OF RNA INTERFERENCE, Chemical Industry Press, 2013: 1192.

[29] Chen Xinquan, Application of optimization method in clustering algorithm, University of Electronic Science and Technology Press, 2014: 1-128.

[30] Li Gui Yuan, Wu Minghua, NON-CODING RNA AND TUMOR, Beijing China, Science Press, 2014: 1-399.

[31] J. E. Krebs, E. S. Goldstein, S. T. Kilpatrick, Lewin's Genes X, Beijing China, Science Press, 2017: 1-994. 